\title{
Mouse and human neutrophils induce anaphylaxis
}

\author{
Friederike Jönsson, ${ }^{1,2}$ David A. Mancardi, ${ }^{1,2}$ Yoshihiro Kita, ${ }^{3}$ Hajime Karasuyama,4,5 \\ Bruno lannascoli, ${ }^{1,2}$ Nico Van Rooijen,6 ${ }^{6}$ Takao Shimizu, ${ }^{3}$ Marc Daëron,, ${ }^{1,2}$ and Pierre Bruhns ${ }^{1,2}$

\begin{abstract}
1'Institut Pasteur, Unité d'Allergologie Moléculaire et Cellulaire, Département d'Immunologie, Paris, France. 2INSERM, U760, Paris, France. ${ }^{3}$ Department of Biochemistry and Molecular Biology, Faculty of Medicine,

The University of Tokyo, Tokyo, Japan. ${ }^{4}$ Department of Immune Regulation, ${ }^{5}$ JST, CREST, Tokyo Medical and Dental University Graduate School, Tokyo, Japan. ${ }^{6}$ Department of Molecular Cell Biology, VU Medical Center, Amsterdam, The Netherlands.
\end{abstract}

\begin{abstract}
Anaphylaxis is a life-threatening hyperacute immediate hypersensitivity reaction. Classically, it depends on $\operatorname{IgE}, \mathrm{Fc} \varepsilon \mathrm{RI}$, mast cells, and histamine. However, anaphylaxis can also be induced by IgG antibodies, and an IgG1-induced passive type of systemic anaphylaxis has been reported to depend on basophils. In addition, it was found that neither mast cells nor basophils were required in mouse models of active systemic anaphylaxis. Therefore, we investigated what antibodies, receptors, and cells are involved in active systemic anaphylaxis in mice. We found that IgG antibodies, Fc $\gamma$ RIIIA and Fc $\gamma$ RIV, platelet-activating factor, neutrophils, and, to a lesser extent, basophils were involved. Neutrophil activation could be monitored in vivo during anaphylaxis. Neutrophil depletion inhibited active, and also passive, systemic anaphylaxis. Importantly, mouse and human neutrophils each restored anaphylaxis in anaphylaxis-resistant mice, demonstrating that neutrophils are sufficient to induce anaphylaxis in mice and suggesting that neutrophils can contribute to anaphylaxis in humans. Our results therefore reveal an unexpected role for IgG, IgG receptors, and neutrophils in anaphylaxis in mice. These molecules and cells could be potential new targets for the development of anaphylaxis therapeutics if the same mechanism is responsible for anaphylaxis in humans.
\end{abstract}

\section{Introduction}

Anaphylaxis is a systemic hyperacute allergic reaction (1) responsible for more than 1,500 deaths per year in the US (2). Anaphylaxis is associated with intense vasodilatation and bronchoconstriction, severe laryngeal edema, drop of cardiac pressure, and hypothermia. As anaphylaxis is a life-threatening medical emergency, the mechanisms thought to be responsible for anaphylaxis have been mostly investigated in animal models. Two types of models have been developed since the initial description of anaphylaxis in dogs (3): active anaphylaxis, in immunized animals, and passive anaphylaxis, in nonimmunized animals injected with antibodies. Indeed, susceptibility to anaphylaxis can be transferred by serum from immunized donors or by purified antibodies.

IgE-induced passive systemic anaphylaxis (PSA) is elicited by injecting mice systemically with IgE antibodies 24-48 hours before an i.v. challenge with specific antigen. The anaphylactic shock that develops within minutes can be easily assessed by monitoring the decrease in body temperature. IgE-induced PSA observed in WT mice was abrogated in mice deficient for FceRI, the high-affinity IgE receptor expressed by mast cells and basophils (4), and in mast cell-deficient $\mathrm{W} / \mathrm{W}^{\mathrm{v}}$ mice (5). It was also abrogated in histidine decarboxylase-deficient mice, which lack histamine (6), and in mice injected with histamine receptor antagonists (7). Anaphylactic symptoms could be induced by an i.v. injection of histamine (6). These findings together demonstrate the mandatory role of mast cells and of FceRI in IgEinduced PSA, and they emphasize the contribution of histamine, contained in mast cell granules that are rapidly released during

Authorship note: Friederike Jönsson and David A. Mancardi contributed equally to this work. Marc Daëron and Pierre Bruhns are co-senior authors.

Conflict of interest: The authors have declared that no conflict of interest exists. Citation for this article: J Clin Invest. 2011;121(4):1484-1496. doi:10.1172/JCI45232. exocytosis. This mechanism has been widely accepted as a paradigm of the anaphylactic reaction.

IgG-induced PSA is elicited by injecting mice systemically with IgG antibodies 2-3 hours before an i.v. challenge with specific antigen. Alternatively, preformed IgG immune complexes (IC) can be injected i.v. Similar symptoms develop, with comparable kinetics, during IgE- and IgG-induced PSA. IgG1 is the dominant antibody subclass raised during humoral responses to protein antigens in mice, and passively administered IgG1-IC are sufficient to induce anaphylaxis. Because the low-affinity IgG receptor Fc $\gamma$ RIIIA was shown to trigger mast cell activation in vitro (8) and passive cutaneous anaphylaxis in vivo (9), it has been generally accepted that these receptors account for IgG1-induced PSA. No published paper formally demonstrated this assumption, but we confirmed that, indeed, IgG1-induced PSA was abrogated in Fc $\gamma$ RIIIA-deficient mice (P. Bruhns and M. Daëron, unpublished observations). Surprisingly, IgG1-induced PSA was not abrogated in mast celldeficient mice (5), but it was reported to be abrogated in basophildepleted mice (10). This suggests that mouse basophils express

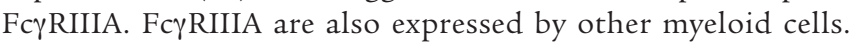
Upon activation, mouse basophils rapidly release granular mediators, including histamine, but also lipid-derived mediators such as platelet-activating factor (PAF). Like histamine, PAF could, by itself, reproduce the clinical signs of an anaphylactic shock when injected in animals (11). PAF, but not histamine, was shown to be responsible for IgG1-induced PSA (10). These findings together indicate that IgG1-IC trigger anaphylaxis through the release of PAF, probably by aggregating Fc $\gamma$ RIIIA on basophils.

Active systemic anaphylaxis (ASA) is elicited by an i.v. injection of antigen into mice immunized with that antigen. Similar symptoms develop with comparable kinetics during ASA and PSA in WT mice. More mice, however, die during ASA than during PSA. Different adjuvants can be used for immunization. It is generally 
accepted that alum favors IgG1 and IgE antibodies, whereas CFA favors IgG2 antibodies. In both cases, however, IgG1 antibodies are the most abundant and IgE the less abundant. ASA was not affected in $\mathrm{C} \varepsilon$-deficient mice, which produce no $\operatorname{IgE}(12)$. Antibodies other than IgE are therefore sufficient to induce ASA. Supporting this conclusion, ASA was not altered in FceRI-deficient mice, but it was abrogated in FcR $\gamma$-deficient mice (5), which express no activat-

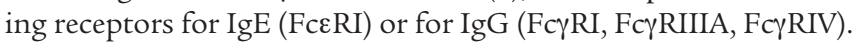
Activating FcRs are therefore mandatory for ASA. ASA was not altered in mast cell-deficient $\mathrm{W}^{\text {sh }} / \mathrm{W}^{\text {sh }}$ or $\mathrm{W} / \mathrm{W}^{\mathrm{v}}$ mice $(5,13)$, in basophil-deficient mice (14), or in basophil-depleted WT mice (10). Neither mast cells nor basophils are therefore mandatory for ASA. Furthermore, ASA-induced decrease in body temperature still occurred in the absence of both cell types, but ASA-associated mortality was abolished (10). Basophils and mast cells can therefore contribute to ASA. Reduced anaphylactic shock was observed in PAF receptor-deficient (PAF-R-deficient) mice (15) and in mice injected with PAF-R antagonists (16). These findings together indicate that antibodies other than IgE, activating FcRs other than FceRI, cell types other than basophils and mast cells, and mediators other than histamine contribute to ASA. These antibodies, FcRs, cells, and mediators are unknown.

We unravel here an unexpected role of neutrophils and an underestimated contribution of $\operatorname{IgG}$ and IgG receptors to anaphylaxis. Neutrophils and basophils both contributed to ASA in WT mice. Neutrophils, however, were sufficient for ASA in genetically modified mice expressing no activating IgG or IgE receptors on mast cells and basophils. Importantly, like murine neutrophils, human neutrophils restored ASA in ASA-resistant mice, suggesting that these cells can contribute to anaphylaxis in humans. Neutrophildependent ASA was mediated by PAF. Neutrophils contributed also to IgG-induced PSA. Finally, 2 IgG receptors, Fc $\gamma$ RIIIA and Fc $\gamma$ RIV, accounted for ASA in WT mice.

\section{Results}

Fc $\gamma I V$ can trigger ASA. An i.v. antigen challenge induced a decrease of body temperature in WT or in mast cell-deficient $\mathrm{W}^{\text {sh }}$ mice immunized with antigen in CFA/incomplete Freund adjuvant (IFA), but not in $\mathrm{FcR}^{-/-}$(officially referred to as Fcerl $1 \mathrm{~g}^{--}$) mice, which lack all activating $\operatorname{IgG}$ and $\operatorname{IgE}$ receptors (data not shown). ASA indeed depends on antibodies. Immunizations in CFA/IFA lead to the production of comparable IgG1 and IgG2 antibody levels in WT and $F c R \gamma^{-/-}$mice and, as expected (5), of higher levels of IgE antibodies in $\mathrm{FcR}^{-/-}$mice than in WT mice (Supplemental Figure 1A; supplemental material available online with this article; doi:10.1172/JCI45232DS1). Nonimmunized WT, but not $\mathrm{FcR \gamma}^{-/}$, mice underwent anaphylaxis upon challenge with antigen if injected with serum from mice immunized with BSA in CFA/IFA (Supplemental Figure 1B).

ASA was not altered in Fcer1a/Fcer2a-double-deficient (FcERI/II-/-) or in Fcgr3a-deficient ( $\left.F c \gamma R I I I A^{-/-}\right)$mice compared with WT mice (Figure 1A). Unexpectedly, ASA was also unaltered in $F c \gamma R I /$ Fc $\mathrm{RIIB} / F c \gamma R I I I A / F c \varepsilon R I / F c \varepsilon R I I^{-/-}(5 \mathrm{KO})$ mice (Figure 1B and Supplemental Table 1). $5 \mathrm{KO}$ mice lack all IgE and IgG receptors except

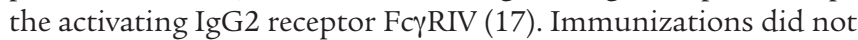
significantly modify the expression of FcyRIV (Supplemental Figure 1C). Anti-Fc $\gamma$ RIV blocking mAbs abolished ASA in $5 \mathrm{KO}$ mice (Figure 1C). FcyRIV can therefore trigger anaphylaxis.

Neutrophils mediate Fc $\gamma I V$-dependent ASA and secrete PAF. Fc $\gamma$ RIV is expressed by monocytes/macrophages and neutrophils $(17,18)$, but not by basophils, mast cells, and eosinophils (Figure 1D).
Monocytes and macrophages can be depleted by injecting toxic liposomes in vivo (19). Both control and toxic liposomes had the same effect on ASA, reducing ASA-associated mortality without altering ASA-associated temperature drop (Figure 1E). Toxic liposomes, but not control liposomes, however, depleted monocytes (example shown in Supplemental Figure 1D). Depletion of monocytes/macrophages induced by toxic liposomes, therefore, did not alter ASA (Figure 1E). Supporting this result, ASA was unaffected in $5 \mathrm{KO}$ mice injected with gadolinium, which inhibits monocyte/macrophage function (Supplemental Figure 1E). Monocyte/macrophages are therefore not mandatory for ASA in $5 \mathrm{KO}$ mice. Noticeably, ASA-associated temperature drop and mortality were abrogated by neutrophil depletion in $5 \mathrm{KO}$ mice (Figure 1F). Anti-Gr1 injections depleted neutrophils, but did not reduce basophil numbers (Supplemental Figure 2, A and B). ASA was restored within 7 days in neutrophil-depleted mice, and it was correlated with blood neutrophil recovery (Figure 1G). Neutrophils, but not monocytes/macrophages, are therefore required for FcyRIV-dependent ASA. Importantly, purified bone marrow neutrophils from $5 \mathrm{KO}$ mice, but not from $\mathrm{FcR \gamma ^{-/ }}$ mice, restored ASAassociated temperature drop in BSA-immunized $F c R \gamma^{-/-}$recipients (Figure 2A). Neutrophils are therefore necessary and sufficient for FcyRIV-dependent ASA. Mediators released and/or secreted by activated neutrophils should therefore be responsible for the anaphylactic shock observed. Among them, PAF (20-22) was shown to mimic anaphylaxis when injected in mice (11). We detected PAF in the supernatant of neutrophils purified from $5 \mathrm{KO}$, but not from $F c R \gamma^{-/-}$, mice stimulated with IgG2b-IC in vitro. Anti-Fc $\gamma$ RIV blocking mAbs abrogated PAF production by neutrophils from $5 \mathrm{KO}$ mice (Figure 2B). PAF may therefore be responsible for Fc $\gamma$ RIVinduced ASA in $5 \mathrm{KO}$ mice.

Neutrophils are immediately and systemically activated during active anaphylaxis. Upon activation, blood neutrophils release granules that contain mediators and enzymes, including myeloperoxidase (MPO). MPO can be released within minutes by activated neutrophils (data not shown and ref. 20) and, under inflammatory conditions, by monocytes/macrophages (23). MPO can oxidize luminol, and oxidized luminol emits luminescence. Luminescence could, indeed, be detected in vivo in WT, but not in $\mathrm{Mpo}^{-/}$, mice injected with luminol and challenged with PMA or LPS (24). Immunized, but not naive, $5 \mathrm{KO}$ mice exhibited a massive, systemic luminescence emission following antigen challenge and luminol injection (Figure 2C and Supplemental Figure 2C). Luminescence was detectable within minutes after antigen challenge and lasted for at least 20 minutes (Figure 2D and Supplemental Figure 2D). These results suggest that neutrophils are systemically activated within minutes in ASA.

FcyRIV, neutrophils, and PAF also contribute to PSA. We investigated whether neutrophil depletion or FcyRIV blocking, which both affect ASA, may also affect an IgG-induced PSA in immunodefi-

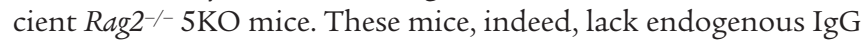

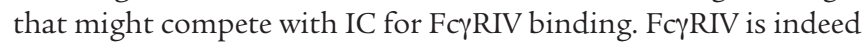
a high-affinity IgG receptor (17). An i.v. injection of monoclonal IgG2b-IC induced a significant, although nonlethal, temperature drop in $R a g 2^{-/-} 5 \mathrm{KO}$ mice, but not in $\operatorname{Rag}^{-/-} \mathrm{FcR} \gamma^{-/-}$mice (Figure 3A). Fc $\gamma$ RIV blockade or neutrophil depletion abolished monoclonal IgG2b-induced PSA in Rag2 $2^{-/}$5KO mice (Figure 3B). Fc $\gamma$ RIV can therefore induce IgG2b-induced PSA that depends on neutrophils. Immunocompetent $5 \mathrm{KO}$ mice also developed IgG2b-induced PSA (data not shown). Because neutrophils from $5 \mathrm{KO}$ mice secrete PAF 

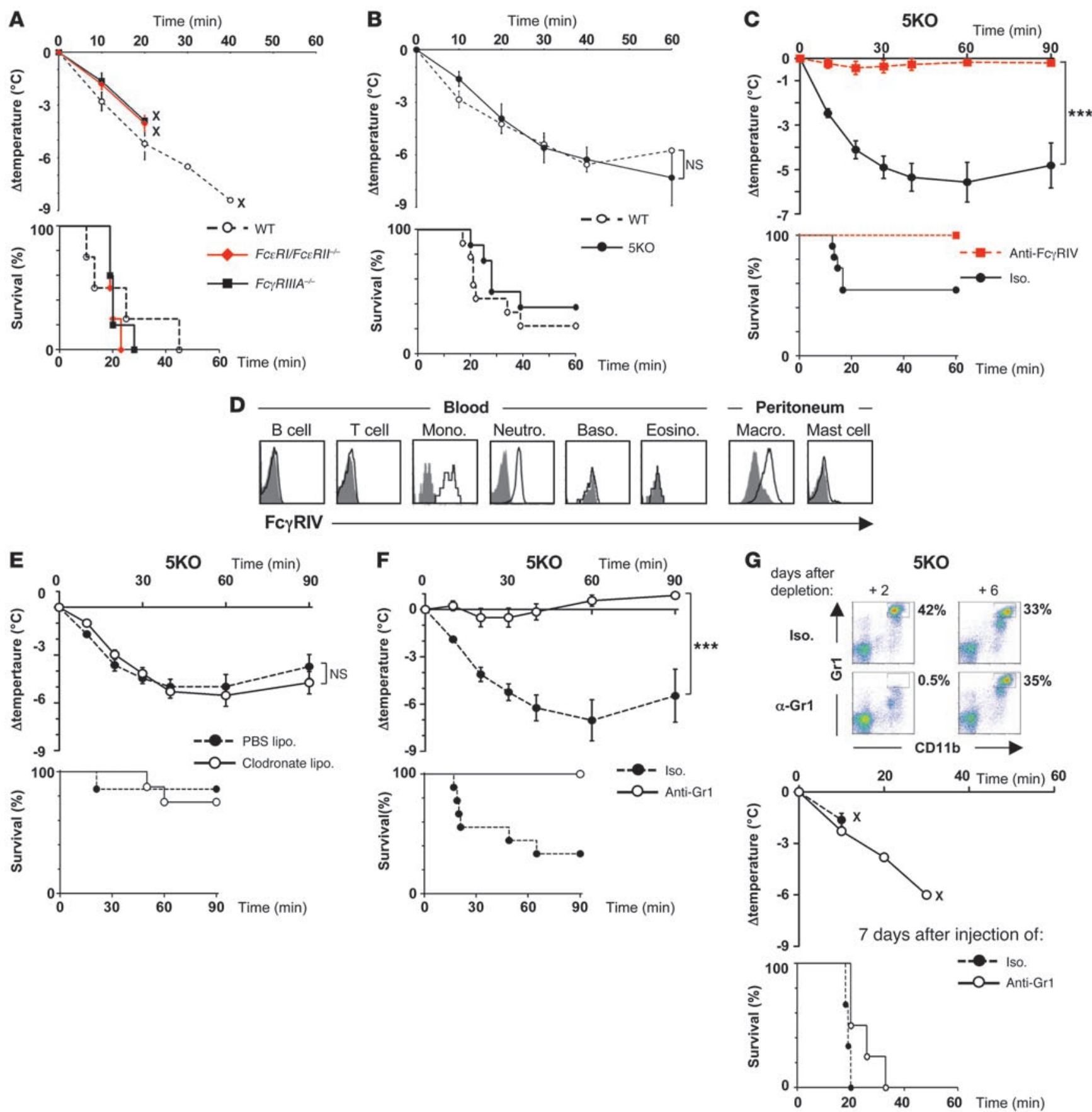

Figure 1

Neutrophils mediate FcyRIV-dependent active anaphylaxis. Indicated mice were immunized and challenged with BSA. Central temperatures and survival rates were monitored. (A) ASA in WT $(n=4), F_{C \gamma} R I I I A^{-/-}(n=5)$, and $F_{C \varepsilon} R I / I I^{--}(n=4)$ mice. (B) ASA in WT $(n=9)$ and 5KO mice $(n=7)$. (C) ASA in $5 \mathrm{KO}$ mice injected with anti-Fc $\gamma \mathrm{RIV}$ mAbs $(n=10)$ or isotype control $(n=11)$ before BSA challenge. (D) Representative expression of FcyRIV on mouse blood and peritoneal cells: B cells (CD19+), T cells (CD4+), monocytes (mono.) (CD11 b+Gr1-), neutrophils (neutro.) $\left(\mathrm{CD} 11 \mathrm{~b}^{+} \mathrm{Gr} 1^{+}\right)$, basophils (baso.) $\left(\mathrm{IgE}+\mathrm{DX} 5^{+}\right)$, eosinophils (eosino.) $\left(\mathrm{Gr} 1^{+}\right.$SiglecF $\left.{ }^{+}\right)$, macrophages (macro.) $\left(\mathrm{CD} 11 \mathrm{~b}^{+} \mathrm{Gr} 1^{-}\right)$, and mast cells $\left(\operatorname{lgE}{ }^{+} \mathrm{CD} 117^{+}\right)$. (E and F) ASA in 5KO mice injected with (E) PBS liposomes (lipo.) $(n=7)$ or clodronate liposomes $(n=8),(\mathbf{F})$ anti-Gr1 mAbs $(n=8)$ or isotype (iso.) control $(n=9)$ before BSA challenge. Data are a compilation of 2 experiments. Note that both PBS and clodronate liposome injections inhibited ASA-associated mortality. (G) Immunized $5 \mathrm{KO}$ mice were injected with anti-Gr1 mAbs or isotype control on day 0 , challenged with BSA on day +1 , retroorbitally bled on days +2 and +6 , but otherwise left untouched until rechallenged with BSA on day +7 . Upper panel: representative density plots of blood leukocytes stained as indicated. Percentages of $\mathrm{Gr} 1^{\text {hi }} \mathrm{CD} 11 \mathrm{~b}^{\text {hi }}$ cells (neutrophils) are indicated. Lower panel: ASA in immunized $5 \mathrm{KO}$ mice at day +7 after depletion (Iso, $n=3$; anti-Gr1, $n=4)$. (A-C and $\mathbf{E}-\mathbf{G}$ ) Data are represented as mean \pm SEM. (A-F) Data are representative from at least 2 independent experiments $\left(\mathbf{A}, 2 ; \mathbf{B}, 5 ; \mathbf{C}, 4 ; \mathbf{D}, 3 ; \mathbf{E}, 2\right.$; and $\mathbf{F}, 4$ experiments). ${ }^{* * *} P<0.001$. X's represent mortality in the $100 \%$ experimental group. 
A
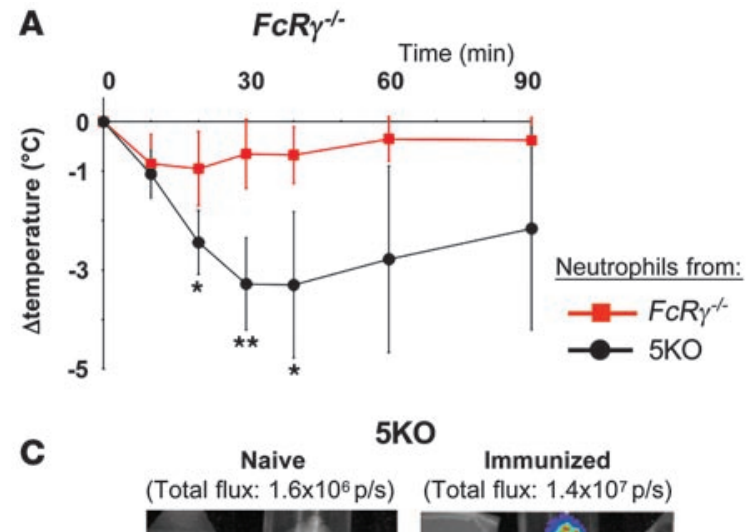

$5 \mathrm{KO}$

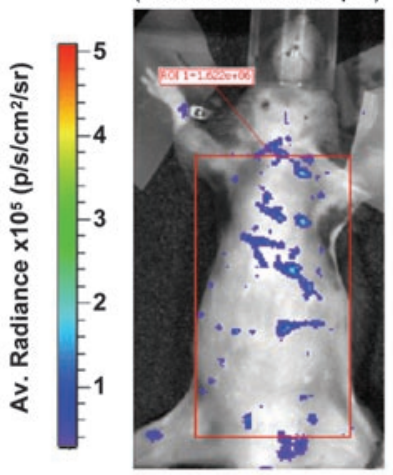

Immunized

(Total flux: $\left.1.4 \times 10^{7} \mathrm{p} / \mathrm{s}\right)$

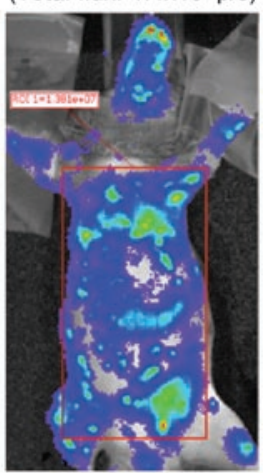

B
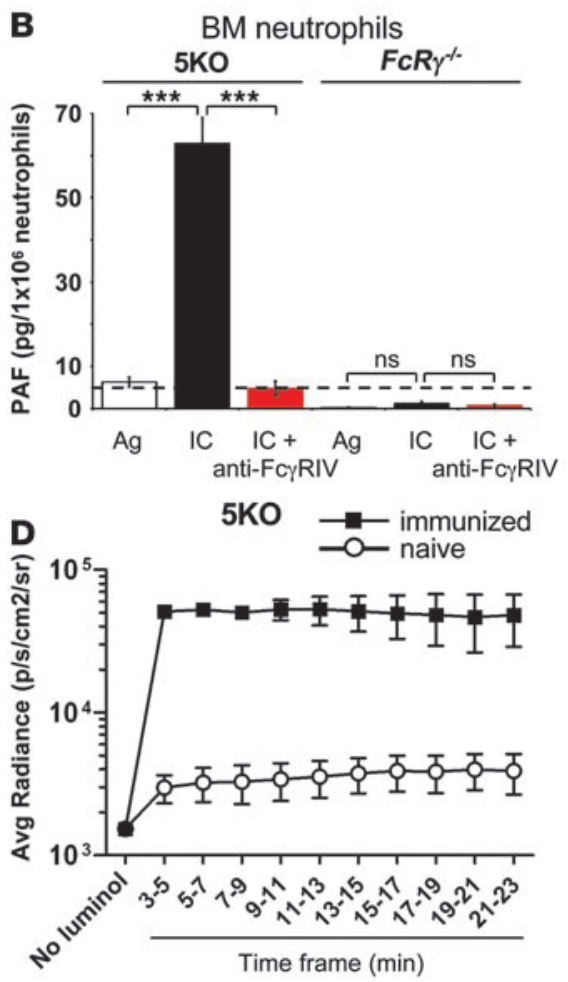

Figure 2

Neutrophil transfer restores ASA, and neutrophils are immediately and systemically activated during ASA. (A) BSA-immunized FcR $\gamma^{-1-}$ mice were injected i.v. with neutrophils from $F_{c} R \gamma^{-1-}$ mice $(n=4)$ or from $5 \mathrm{KO}$ mice $(n=5)$, challenged with $\mathrm{BSA}$, and central temperatures measured. Statistical differences are indicated for each time point if significant. Note that no mortality was observed during this experiment. (B) Purified bone marrow neutrophils from $5 \mathrm{KO}$ or $\mathrm{FcR}_{c} \gamma^{-1-}$ mice were stimulated with antigen alone (Ag) or with IgG IC, or preincubated with anti-Fc $\gamma \mathrm{RIV}$ Abs before stimulation with IC (IC plus anti-Fc $\gamma$ RIV), and PAF concentration was determined in culture supernatants. Means of triplicates are represented. (C) Naive or BSA-immunized 5KO mice were anesthetized, challenged with BSA $(t=0)$, and injected with luminol ( $t=5$ minutes). Representative images show color-coded maps of photon flux superimposed on black and white photographs of mice (15- to 20-minute time frame after challenge) $(n=2)$. (D) Time course of photon fluxes from naive and BSA-immunized 5 KO mice $(n=3)$ following BSA challenge $(t=0)$. (A and D) Data are represented as mean \pm SEM. (C and $\mathbf{D})$ Data are representative from 2 independent experiments. ${ }^{*} P<0.05 ;{ }^{* *} P<0.01 ;{ }^{* \star *} P<0.001$.

when stimulated in vitro with IgG2b-IC (Figure 2B), we measured $\mathrm{PAF}$ in the plasma of $5 \mathrm{KO}$ mice undergoing neutrophil-dependent IgG2b-induced PSA. We detected elevated PAF levels in the plasma of challenged, but not in nonchallenged (no detectable PAF; not shown), 5KO mice (Figure 3C). Fc $\gamma$ RIV blockade abolished the increase in circulating PAF levels. Elevated PAF levels in plasma therefore correlate with Fc $\gamma$ RIV-triggered, neutrophil-dependent PSA. Surprisingly, Fc $\gamma$ RIV blockade or neutrophil depletion abolished monoclonal IgG2b-induced PSA in WT mice also (Figure 3D). Fc $\gamma$ RIV is therefore responsible for IgG2b-induced neutrophildependent PSA in WT mice.

A nonlethal PSA could also be observed in Rag2-/- $5 \mathrm{KO}$ mice injected with IC made of GPI and $\mathrm{K} / \mathrm{BxN}$ serum (GPI/anti-GPIinduced PSA) (Figure 3E), which contains polyclonal IgG1 and IgG2 anti-GPI antibodies $(25,26)$. Neutrophil depletion abolished

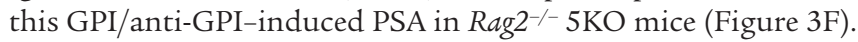
As expected, Fc $\gamma$ RIV blockade only slightly reduced GPI/anti-GPIinduced PSA in WT mice. Surprisingly, however, the depletion of neutrophils, which express Fc $\gamma$ RIV and Fc $\gamma$ RIIIA, was sufficient to abolish GPI/anti-GPI-induced PSA in these mice (Figure 3G). Similar results were observed in $5 \mathrm{KO}$ mice (data not shown). Whereas basophils have been reported to mediate monoclonal IgG1-induced PSA (10), neutrophil depletion, but not basophil depletion, abolished GPI/anti-GPI-induced PSA in the same experiment (Figure $3 \mathrm{H}$ ). Similarly, whereas mast cells have been reported to contribute to monoclonal IgG1-induced PSA (5), mast cell-deficient $W^{\text {sh }}$ mice showed unaltered GPI/anti-GPI-induced PSA. Neutrophil depletion abolished GPI/anti-GPI-induced PSA in $\mathrm{W}^{\text {sh }}$ mice as efficiently as in WT mice, whereas basophil depletion had no effect (Figure 3I). Together, these results demonstrate that neutrophils, but not mast cells or basophils, are mandatory for polyclonal IgG-induced PSA in nonimmunized WT mice.

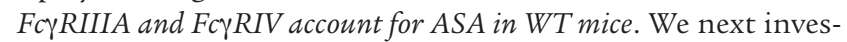
tigated the contribution of activating Fc receptors to ASA in WT mice. WT mice express 1 activating IgE receptor, FceRI, and 3 activating IgG receptors, Fc $\gamma$ RI, Fc $\gamma$ RIIIA, and Fc $\gamma$ RIV. No anti-FceRI- or anti-Fc $\gamma$ RI-blocking antibodies are available. The recently described (27) mAb 275003, which is specific for Fc $\gamma$ RIIIA (Figure 4A and Supplemental Figure 3, A and B), and which can block the binding of IgG-IC to FcyRIIIA in vitro (Supplemental Figure 3C), abolished FcyRIIIA-dependent (9) IgG-induced PSA (Figure 4B). Fc $\gamma$ RIIIA blockade also significantly reduced ASA-associated temperature drop and mortality in WT mice (Figure 4, C and D). FcyRIV blockade reduced ASAassociated temperature drop similarly to Fc $\gamma$ RIIIA blockade, but reduced mortality less efficiently (Figure 4D). Concomitant 

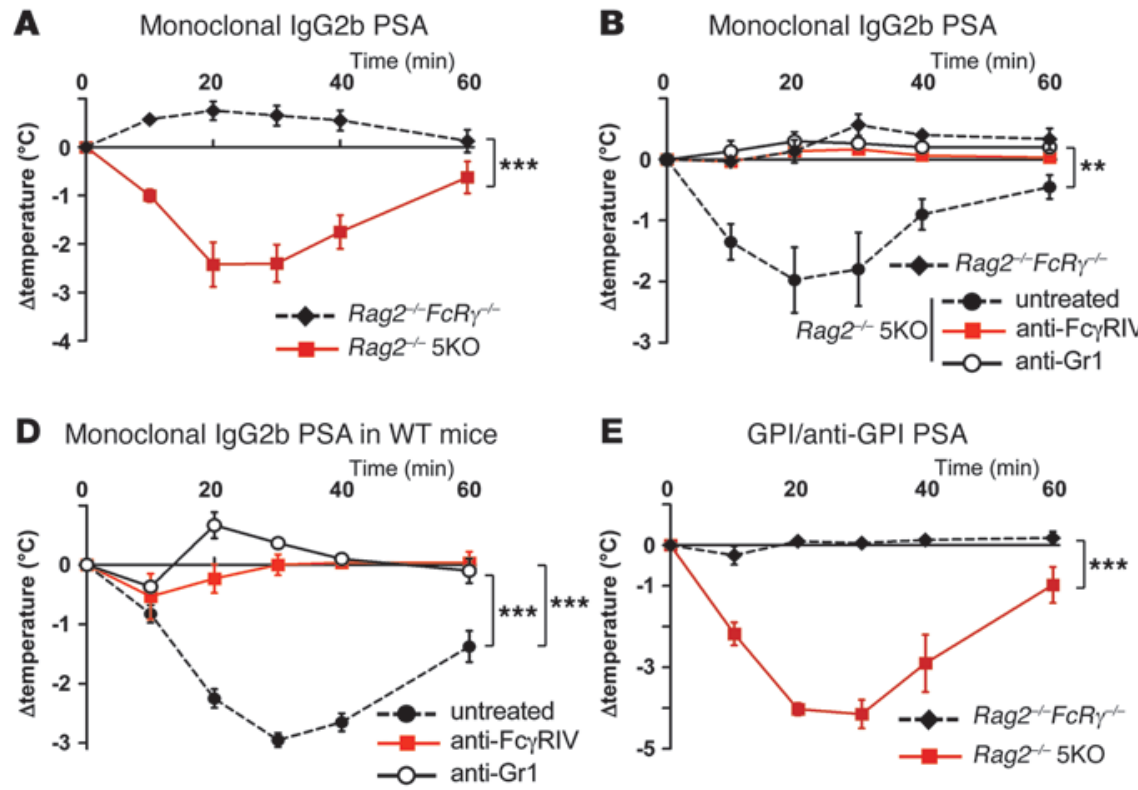

G GPI/anti-GPI PSA in WT mice
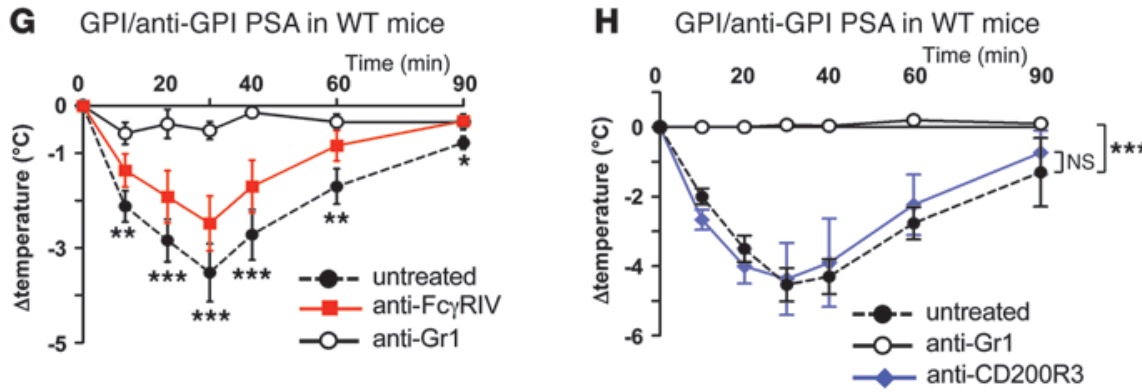

\section{Monoclonal IgG2b PSA in $5 \mathrm{KO}$ mice}

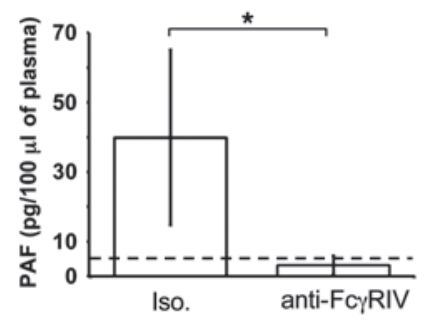

\section{F GPI/anti-GPI PSA in Rag2 $2^{-1} 5 \mathrm{KO}$ mice}

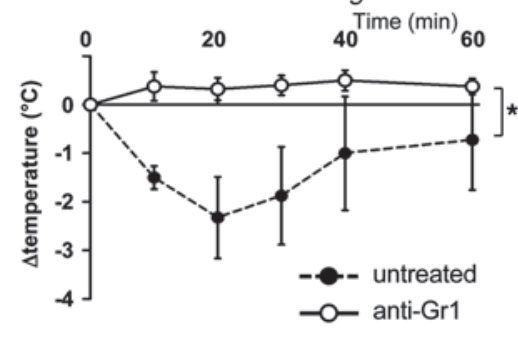

\section{GPI/anti-GPI PSA in $\mathrm{W}^{\text {sh }}$ mice}

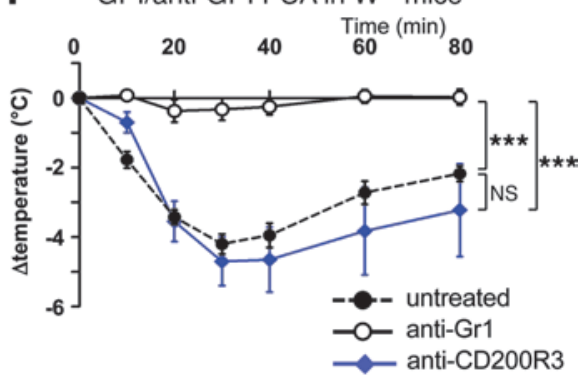

Figure 3

Neutrophils and FcyRIV account for IgG2b-IC induced PSA in WT mice, and neutrophils account for GPI/anti-GPI-PSA in WT mice. (A, B, and D) Indicated mice were injected with preformed IgG2b-IC (monoclonal IgG2b anti-DNP mAb plus DNP-HSA), and central temperatures were monitored (A, $n=4$; B, $n=3$; $\mathbf{D}, n=3)$. (C) $5 \mathrm{KO}$ mice were preinjected or not with anti-FcyRIV Abs before challenge with IgG2b-IC. Plasma was collected 20 minutes after challenge, and PAF concentration was determined. Means of triplicates are represented. (E-I) Mice were injected with indicated $\mathrm{mAbs}$ or isotype controls before injection of preformed polyclonal IgG-IC (GPI/anti-GPI). Central temperatures were monitored (E, $n=4$; $\mathbf{F}, n=4 ; \mathbf{G}, n=5 ; \mathbf{H}, n=4 ; \mathbf{I}, n=4)$. (G) Statistical differences between the untreated and the anti-Gr1-treated groups are indicated for each time point if significant. (A-I) Data are represented as mean \pm SEM. (A, B, and D-I) Data are representative of 2 independent experiments. Note that no mortality was observed in all these experiments. ${ }^{\star} P<0.05 ;{ }^{\star \star} P<0.01 ;{ }^{* \star \star} P<0.001$.

Fc $\gamma$ RIIIA and Fc $\gamma$ RIV blockade, however, were necessary to abolish ASA in WT mice (Figure 4, D and E). Fc $\gamma$ RIIIA and Fc $\gamma$ RIV therefore account for ASA in WT mice.

Neutrophils and basophils contribute to ASA in WT mice. FcyRIIIA and Fc $\mathrm{RIV}$ are both expressed by neutrophils, monocytes, and macrophages. Fc $\gamma$ RIIIA, but not Fc $\gamma$ RIV, is expressed also on basophils, eosinophils, and mast cells (Figure 5A and Figure 1D). All these cell types can potentially contribute to ASA. Inhibition of monocyte/macrophages (Figure $5 \mathrm{~B}$ ) or depletion of eosinophils (Supplemental Figure 3D) did not affect ASA in WT mice. Importantly, neutrophil depletion reduced temperature drop and prevented ASA-associated death in WT mice (Figure 5C). Basophil depletion (example shown in Supplemental Figure $3 \mathrm{E})$ had no effect unless neutrophils were also depleted, suggesting a dominant role for neutrophils in ASA (Figure 5C). Similar results were obtained in mast cell-deficient $\mathrm{W}^{\text {sh }}$ mice (Figure 5D) and in FcyRIIIA ${ }^{-/-}$mice that express no activating
FcyRs on mast cells and basophils (Figure 5E). ASA in WT mice is therefore unaffected by a deficiency in a single cell population, except that of neutrophils.

We observed that the proportion of blood neutrophils significantly increased following immunizations with antigen in CFA/IFA. Neutrophilia is not specific to this adjuvant, as it was also observed following immunization with alum or with alum plus Pertussis toxin (Figure 6A). This observation could possibly explain the dominant contribution of neutrophils to ASA following CFA/IFA immunizations. To test this hypothesis, we delayed the antigenic challenge for several weeks until neutrophil numbers dropped back to baseline. Six weeks after immunization, neutrophil numbers in $5 \mathrm{KO}$ mice immunized with BSA in CFA/IFA were comparable to neutrophil numbers in naive mice (Figure 6B), while the levels of anti-BSA antibodies in the serum remained high (Figure 6C). When challenged with BSA, these $5 \mathrm{KO}$ mice developed ASA, as expected, and ASA-associated temperature drop and mortality were both dependent on neutrophils 
$\mathbf{A}$
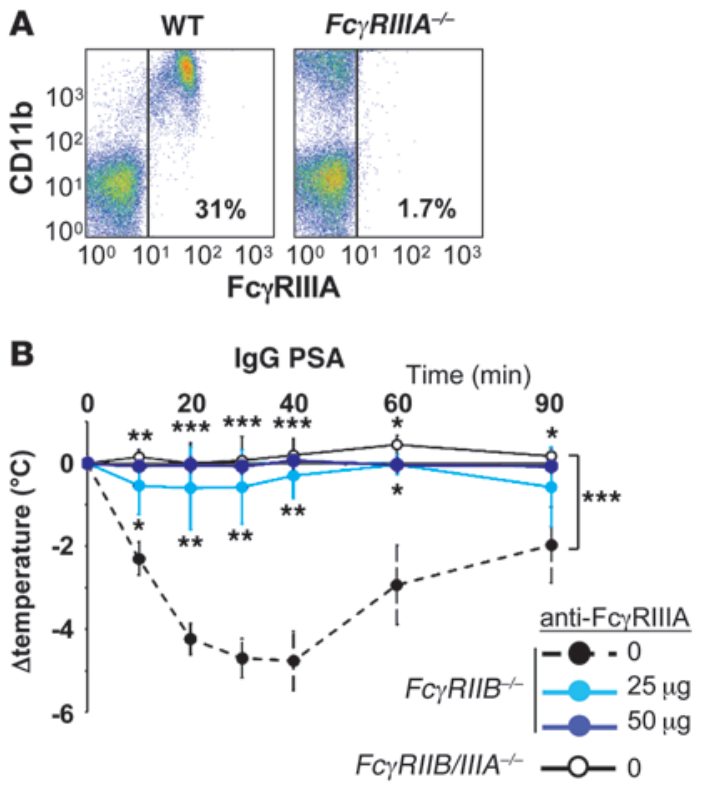

D
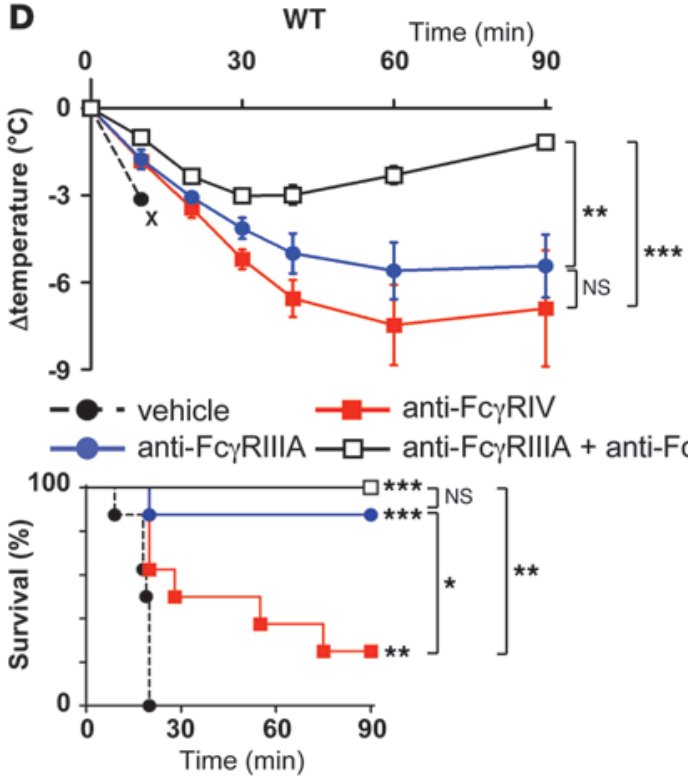
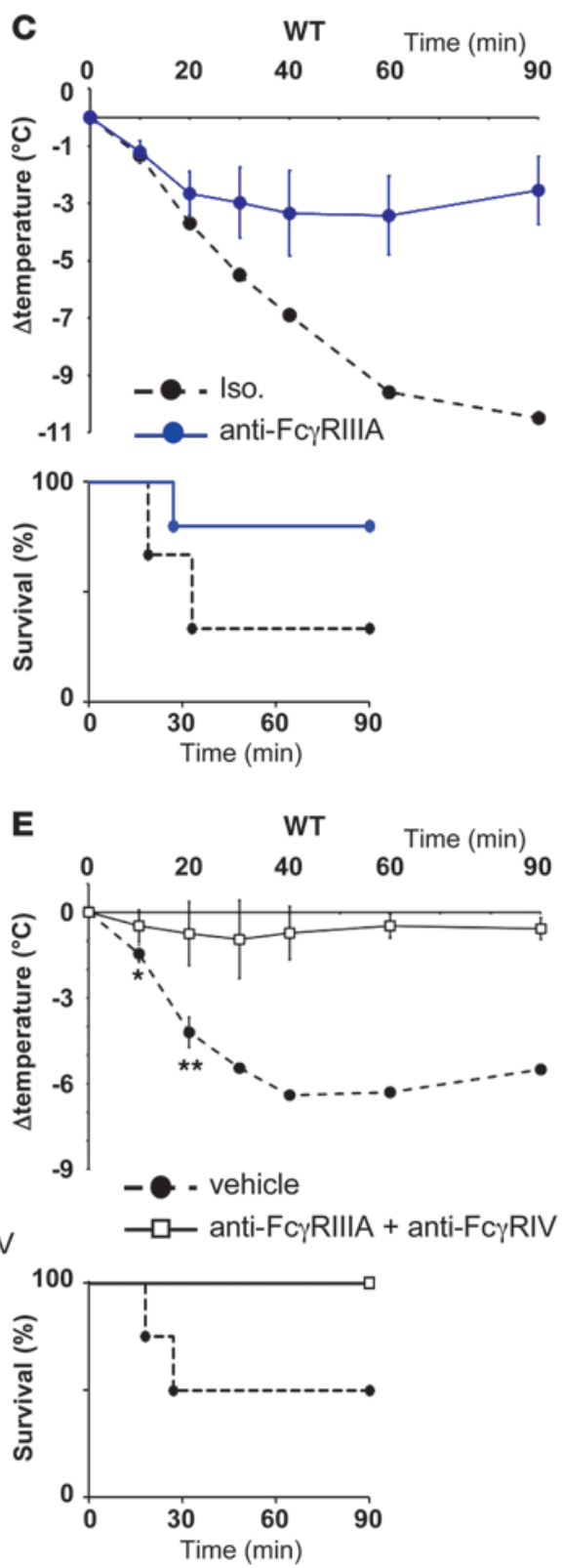

Figure 4

Fc $\gamma$ RIIIA and Fc $\gamma$ RIV account for ASA in WT mice. (A) Representative density plots of CD11b and FcyRIIIA expression on blood leukocytes from

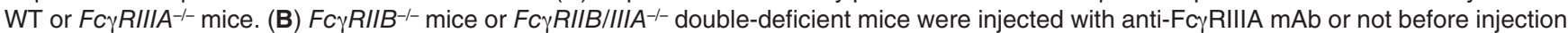
with IgG1-IC $(n=3)$. Central temperatures were monitored. Statistical differences between groups treated with 0 and $25 \mu \mathrm{g}$ and those treated with 0 and $50 \mu \mathrm{g}$ are indicated under and over the horizontal axis, respectively, for each time point if significant. (C-E) Indicated mice were immunized and challenged with BSA. Central temperatures and survival rates were monitored. (C) ASA in WT mice injected with anti-Fc RIIIA $(n=5)$ or vehicle $(n=3)$ before BSA challenge. (D) ASA in WT mice injected with vehicle $(n=8)$, anti-FcyRIIIA mAbs $(n=7)$, anti-Fc RIV mAbs $(n=8)$, or both mAbs $(n=7)$. Statistical differences between the vehicle-treated group and each experimental group are indicated at the right end of each curve. (E) ASA in WT mice injected with indicated mAbs before BSA challenge $(n=4)$. (A-E) Data are represented as mean \pm SEM and are representative of 2 independent experiments. ${ }^{*} P<0.05$; ${ }^{* *} P<0.01$; ${ }^{* \star} P<0.001$. X's represent $100 \%$ mortality in the vehicle group.

(Figure 6D). The dominant role for neutrophils in ASA is therefore not due to higher neutrophil numbers in immunized mice.

PAF mediates neutrophil-dependent ASA. Because neutrophils play a dominant role in ASA in $5 \mathrm{KO}$ mice and in WT mice, because neutrophils secrete PAF in vitro (Figure $2 \mathrm{~B}$ ), and because PAF concentration is elevated in plasma during neutrophil-dependent PSA
(Figure 3C), we analyzed the contribution of PAF to ASA in $5 \mathrm{KO}$ and in WT mice. Two PAF-R antagonists (Figure 7A), but not a histamine receptor- 1 antagonist (Figure 7B), markedly reduced ASA in $5 \mathrm{KO}$ mice. PAF-R antagonists also abolished ASA-associated death and inhibited temperature drop in WT mice, whereas histamine receptor-1 antagonist had a much milder effect (Figure 7C). 
A

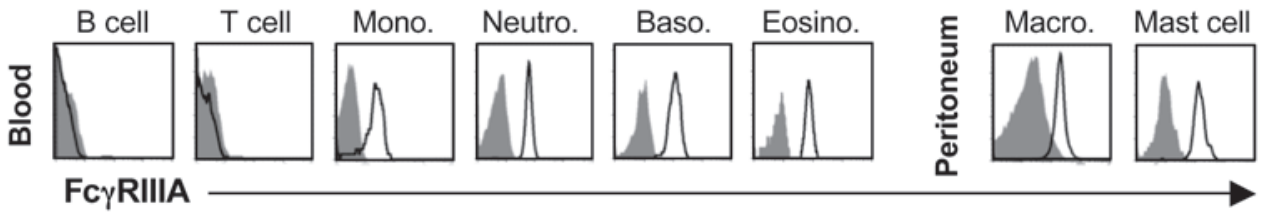

B
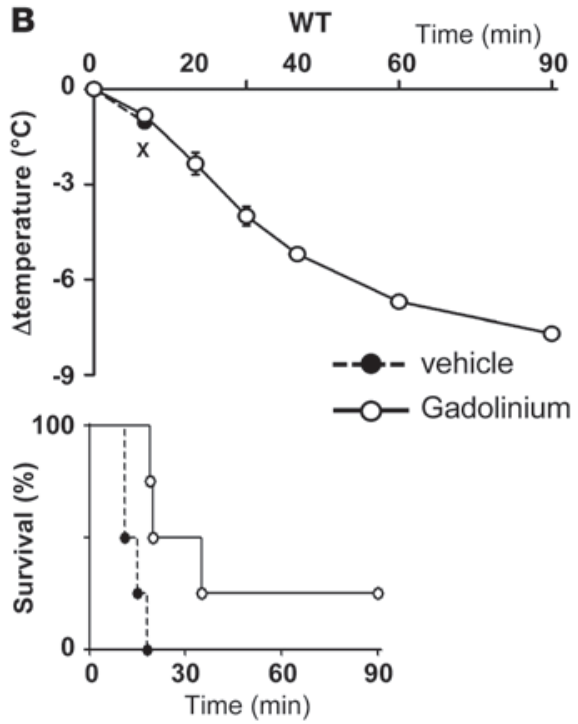

D
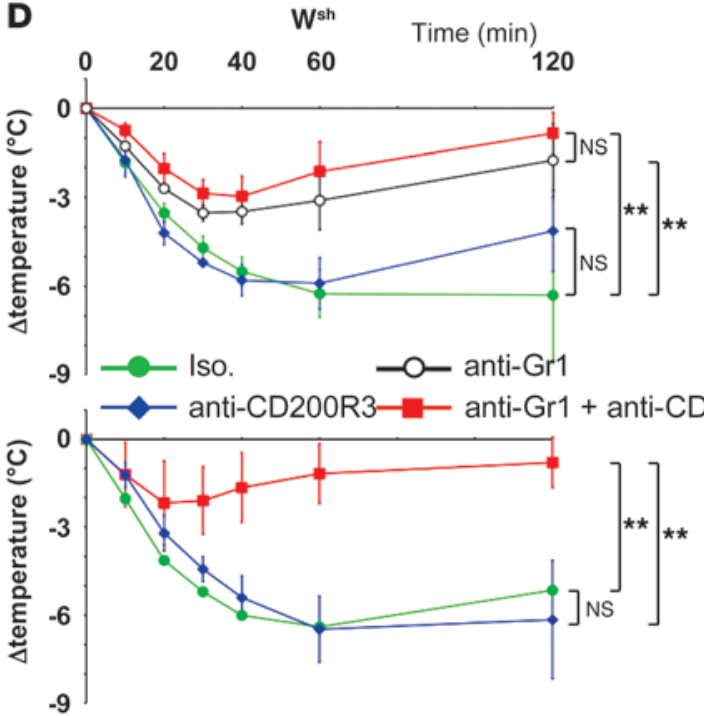

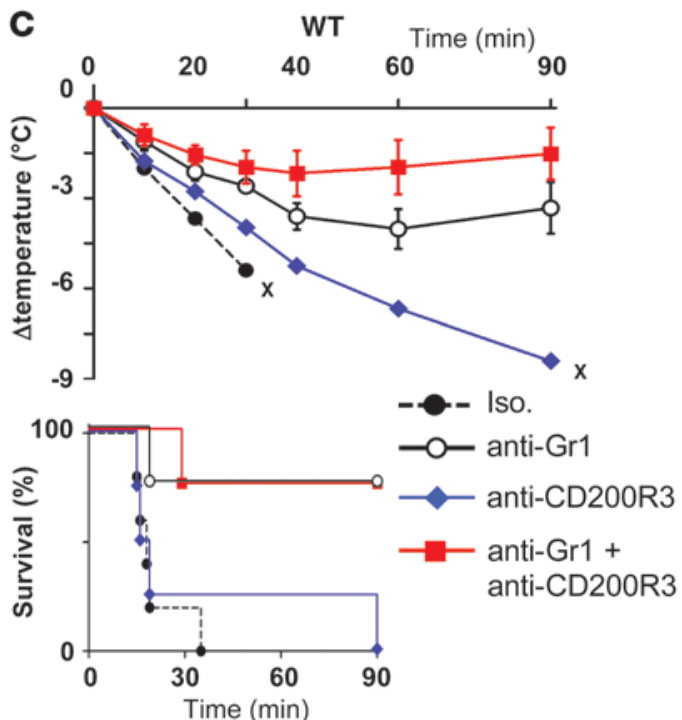

$\mathbf{E}$

FC $\gamma$ RIIIA ${ }^{--}$Time $(\min )$
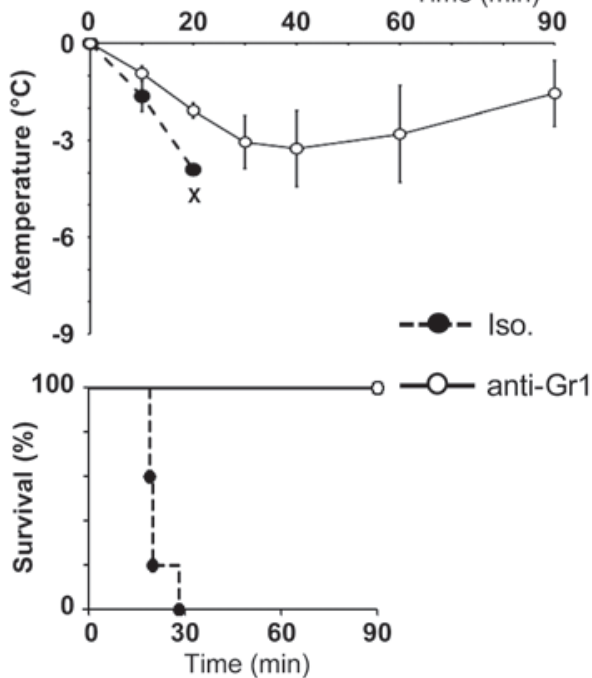

\section{Figure 5}

Neutrophils and basophils contribute to active anaphylaxis in WT mice. (A) Representative histogram plots of FcyRIIIA expression in WT mice on cell populations identified as in Figure 1D. (B-E) Indicated mice were immunized against BSA and challenged with BSA. Central temperatures and survival rates were monitored. (B) WT mice were injected with gadolinium or vehicle before BSA challenge $(n=4)$. (C) WT mice were injected with anti-Gr1, anti-CD200R3, anti-Gr1 plus anti-CD200R3 mAbs $(n=4)$, or isotype controls $(n=5)$ before BSA challenge. Survival of the isotype-treated group is statistically different from the anti-Gr1 and from the anti-Gr1 plus anti-CD200R3 groups $(P<0.05)$, but not from the anti-CD200R3 group. (D) Wsh mice were injected with anti-CD200R3 (top: $n=3$; bottom: $n=4$ ), anti-Gr1 (top: $n=4$ ), anti-Gr1 plus anti-CD200R3

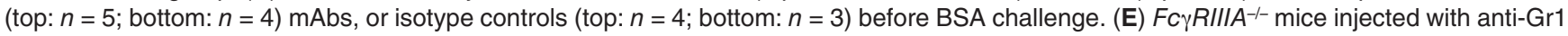
mAbs or isotype control before BSA challenge $(n=5)$. (B-E) Data are represented as mean \pm SEM. (A-E) Data are representative of 2 independent experiments. ${ }^{\star \star} P<0.01$. X's represent $100 \%$ mortality in the experimental group.

PAF production requires cytosolic phospholipase $\mathrm{A}_{2}$ (cPLA2) (2830). ASA was strongly inhibited in cPLA2-deficient mice (Figure 7D). PAF may therefore account for neutrophil-dependent ASA in $5 \mathrm{KO}$ mice and contributes to ASA in WT mice.
Human neutrophils restore ASA in FcR ${ }^{-/-}$mice. Like murine neutrophils (Supplemental Figure 4A), human neutrophils express FcRs. The only activating FcRs expressed by neutrophils from normal donors are Fc $\gamma$ RIIA (Figure 8A). Human neutrophils, 

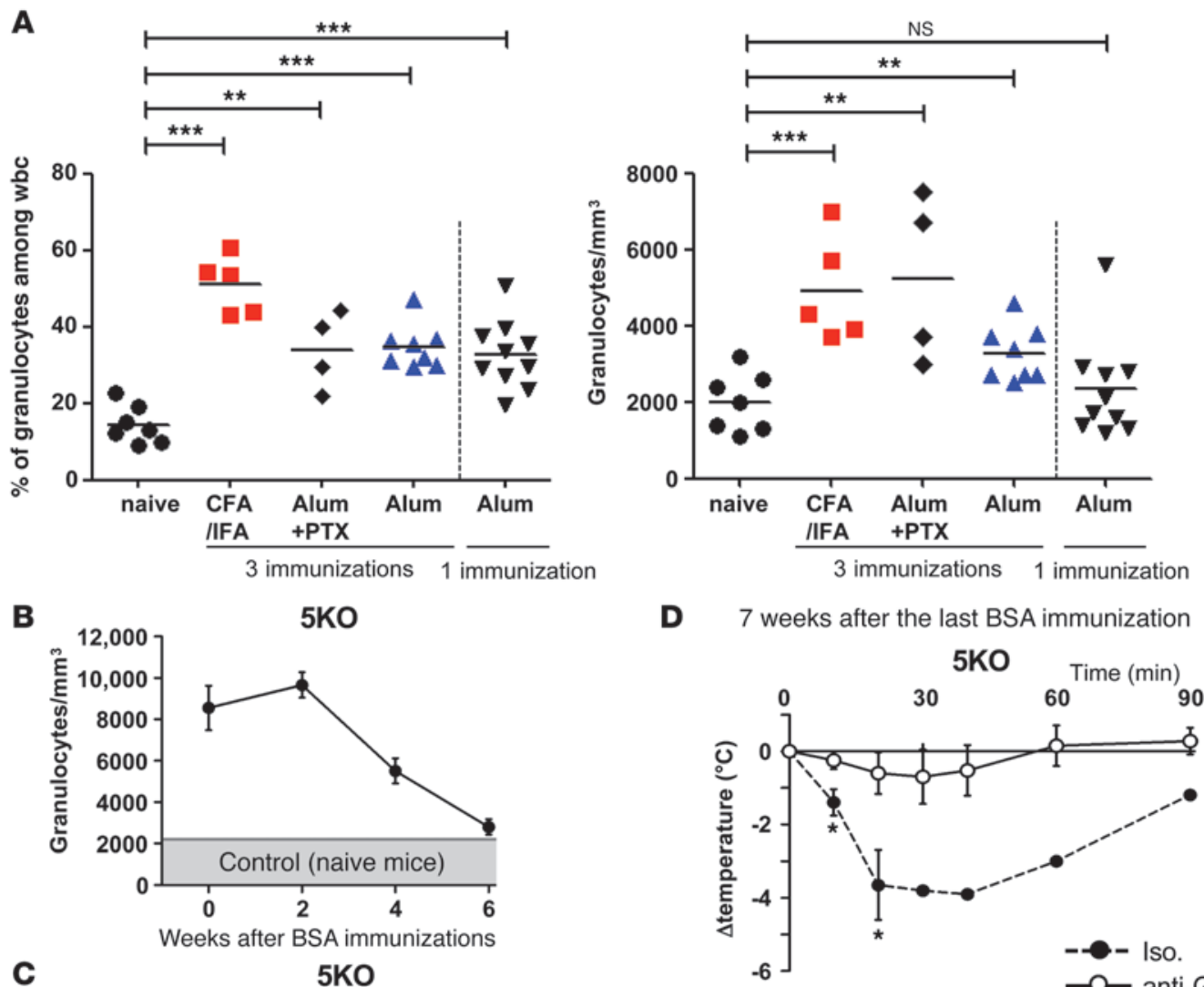

D 7 weeks after the last BSA immunization
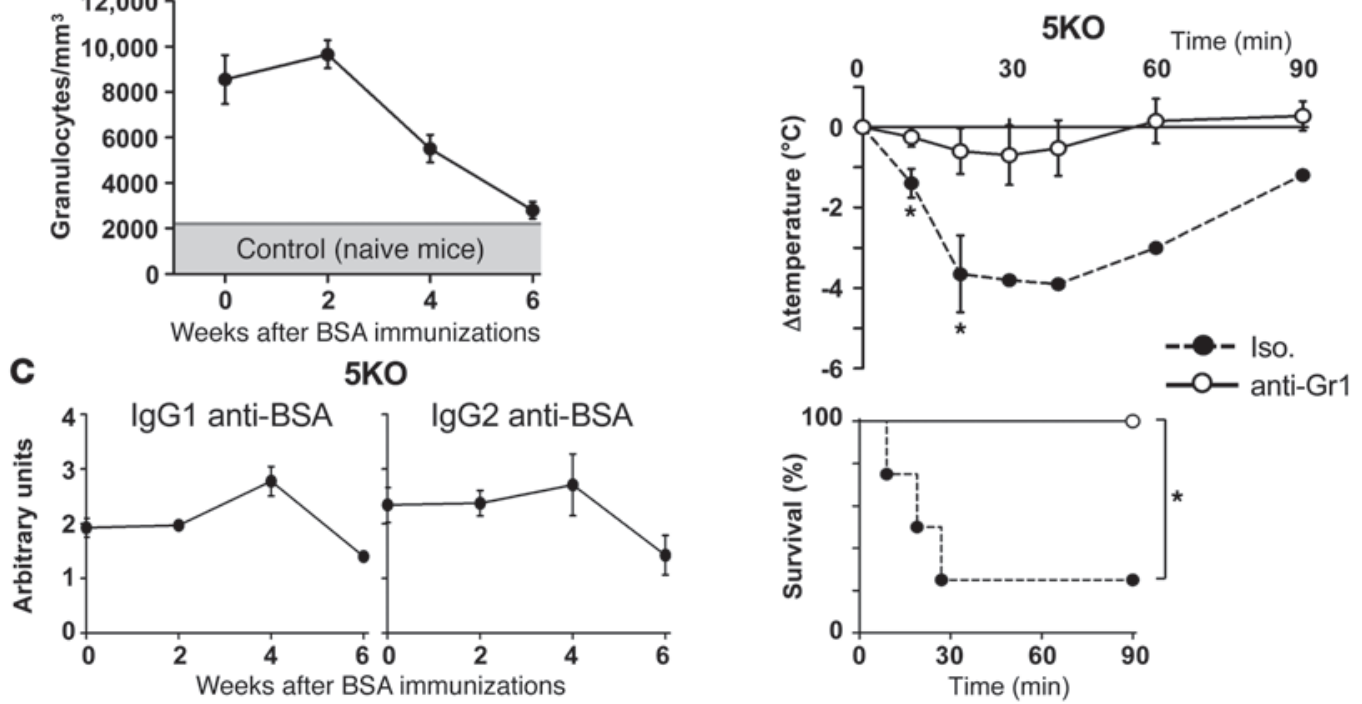

Figure 6

High neutrophil numbers are not responsible for the predominant contribution of neutrophils to ASA. (A) WT mice were left untreated (naive, $n=7$ ) or were injected 3 times with BSA in the indicated adjuvant (CFA/IFA, $n=5$; alum plus PTX, $n=4$; alum, $n=8$ ) or 1 time only with BSA in alum $(n=10)$. The proportion of granulocytes among wbc and the absolute granulocyte counts in blood 7 days after the last immunization is represented as individual results and mean. PTX, pertussis toxin. (B and C) Absolute granulocyte counts (B) and anti-BSA antibody levels (C) in blood of $5 \mathrm{KO}$ mice over time after the last immunization $(t=0)$ in CFA/IFA $(n=8)$. (D) Mice from $\mathbf{B}$ and $\mathbf{C}$ were injected with indicated mAbs and challenged with BSA 7 weeks after the last immunization $(n=4)$. Statistical significance is indicated. (B-D) Data are represented as mean \pm SEM. ${ }^{*} P<0.05 ;{ }^{* *} P<0.01 ;{ }^{* * *} P<0.001$.

indeed, do not express Fc $\gamma$ RI, FceRI, or Fc $\gamma$ RIIIA. They, however, express the GPI-anchored Fc $\gamma$ RIIIB $(31,32)$. Fc $\gamma$ RIIA, but not Fc $\gamma$ RIIIB, could bind IC made with mouse IgG1, IgG2a, or IgG2b (Figure 8B). Human neutrophils could be activated in vitro by IC made with mouse polyclonal IgG (Figure $8 \mathrm{C}$ ) or mouse monoclonal IgG1 or IgG2b (Supplemental Figure 4B), as could murine neutrophils from WT and 5KO, but not from $F c R \gamma^{-/-}$, mice (Supplemental Figure 4C). Neutrophils purified from normal human donors could restore ASA when injected i.v. into immunized $F c R \gamma^{-/-}$mice prior to antigen challenge (Figure 8, D-F). Importantly, the same neutrophils purified from individual donors induced no anaphylaxis upon antigen challenge in nonimmunized mice (Figure 8, E and F). The intensity of the shock was proportional to the number of human neutrophils transferred into $\mathrm{FcR}^{-/-}$mice. Human neutrophils can therefore substitute for murine neutrophils in ASA.

\section{Discussion}

We show here that IgG antibodies, activating Fc $\gamma$ Rs, neutrophils, and PAF are the main players in ASA, whereas IgE antibodies (12), FceRI (5), mast cells $(5,13)$, and histamine do not play a major role. Several cell types have been involved in anaphylaxis; among them are mast cells and basophils. We demonstrate that neutrophils are not only sufficient to induce ASA, but play a dominant role. Indeed, neutrophil depletion, but not basophil depletion, eosinophil depletion, monocyte/macrophage inhibition or mast cell deficiency, abrogated ASA-associated death, and reduced temperature drop in WT mice. Importantly, transfer of mouse neu- 
A

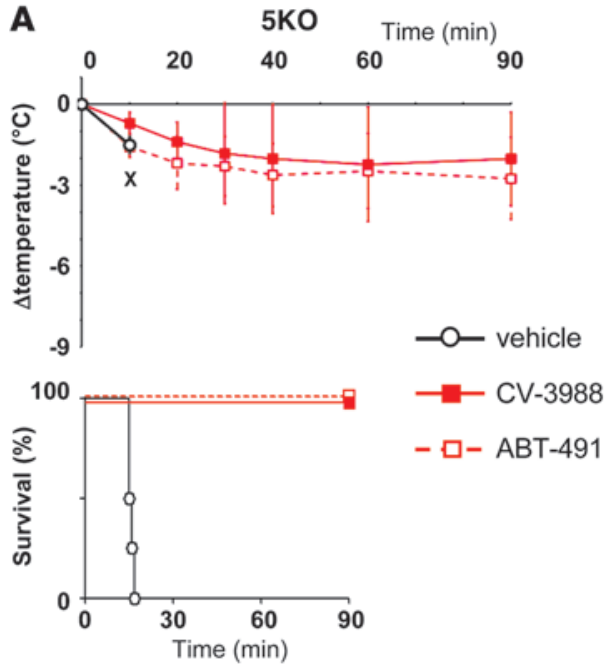

C
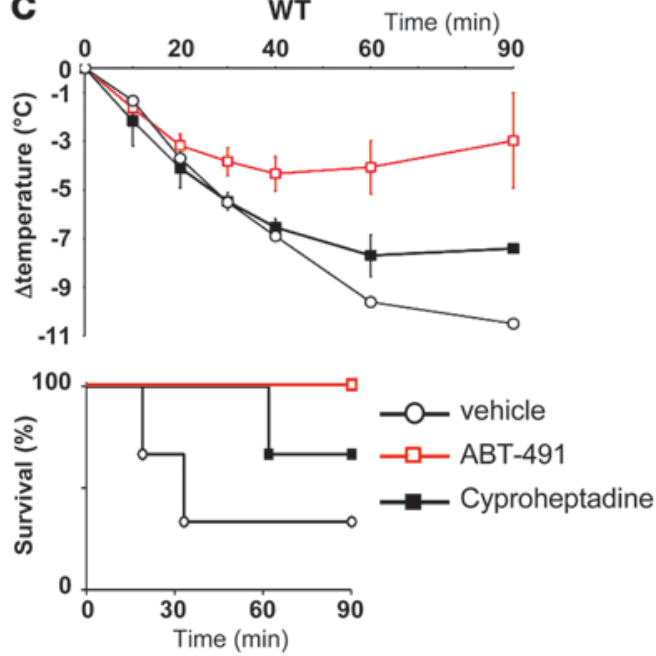

B

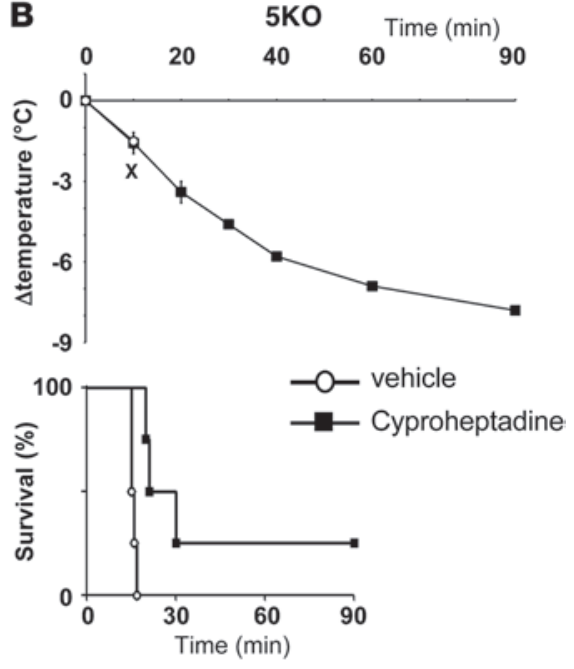

D
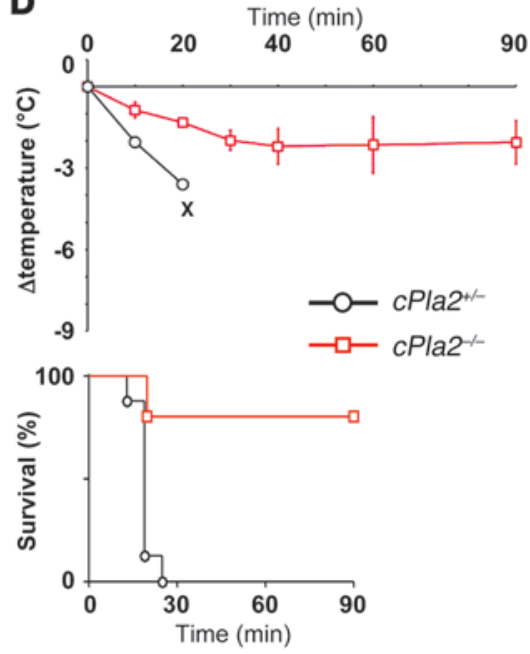

Figure 7

PAF mediates neutrophil-dependent active anaphylaxis. Indicated mice were immunized and challenged with BSA. Central temperatures and survival rates were monitored. (A and $\mathbf{B})$ ASA in $5 \mathrm{KO}$ mice injected (A) with vehicle or indicated PAF-R antagonists $(n=4)$ or (B) with vehicle or cyproheptadine $(n=4)$ before BSA challenge. (C) ASA in WT mice injected with ABT-491, cyproheptadine, or vehicle before BSA challenge $(n=3)$. (D) ASA in cPla2 ${ }^{-/}$mice $(n=5)$ or heterozygous littermate controls $(n=8)$. (A-D) Data are represented as mean \pm SEM and are representative of 2 independent experiments. X's represent $100 \%$ mortality in the experimental group. trophils expressing Fc $\gamma$ RIV, but not of neutrophils expressing no activating $\mathrm{Fc} \gamma \mathrm{Rs}$, restored ASA in $\mathrm{FcR} \gamma^{-/-}$mice. Neutrophil activation could be visualized in vivo within minutes in mice undergoing ASA. Although monocytes/macrophages were reported to be involved in a model of anaphylaxis induced by an i.v. injection of goat IgG in mice immunized with goat IgG anti-mouse IgD (33), we could not detect any role for monocytes/macrophages in ASA in mice immunized with antigen in CFA/IFA. The depletion of eosinophils did not impair ASA either. Basophil depletion, which did not affect ASA by itself, further reduced ASA when combined with neutrophil depletion. Basophils therefore contribute to ASA together with neutrophils, but neutrophils play a dominant role. One possible explanation is that neutrophils are much more numerous than basophils in blood.

Noticeably, we observed neutrophilia following immunization of mice with antigen in CFA/IFA. We excluded that neutrophilia accounted for the dominant contribution of neutrophils to ASA by delaying antigen challenge until neutrophil numbers in immunized mice were comparable to those in naive mice. Under these conditions, neutrophils were also mandatory for ASA in $5 \mathrm{KO}$ mice. We found that neutrophils also predominantly contributed to IgG-induced PSA (whether induced by monoclonal IgG2b-IC or polyclonal-IC) in nonimmunized WT mice that have normal numbers of neutrophils. We also observed neutrophilia following immunizations with alum or with alum plus Pertussis toxin. In preliminary experiments, neither neutrophil depletion nor basophil depletion significantly reduced temperature drop, but a depletion of both cell types abolished ASA in mice immunized with antigen in alum (our unpublished observations). Taken together, our results demonstrate that neutrophils contribute to anaphylactic shock in 2 models of ASA, i.e., following immunization in CFA/ IFA or in alum, and in 2 models of PSA, i.e., induced by polyclonal IgG-IC or monoclonal IgG2b-IC.

Two mediators, PAF and histamine, were found to play a critical role in experimental anaphylaxis. Mast cells, basophils and, apparently, neutrophils (34) can release histamine. Histamine accounts for IgE-induced PSA but not for IgG1-induced PSA, whereas PAF accounts for IgG1-induced PSA but not IgE-induced PSA (10). We found that PAF has a dominant role in ASA. Indeed, PAF-R antagonists, but not histamine receptor $\mathrm{H} 1$ antagonists, markedly reduced temperature drop and prevented death in ASA in mice immunized with antigen in CFA/IFA. In agreement with these results, ASA-associated heart rate and arterial pressure reduction were strongly impaired in PAF-R-deficient mice (15), suggesting that ASA-associated temperature drop and mortality may also be inhibited in these mice. Indirectly supporting this assumption, 
A
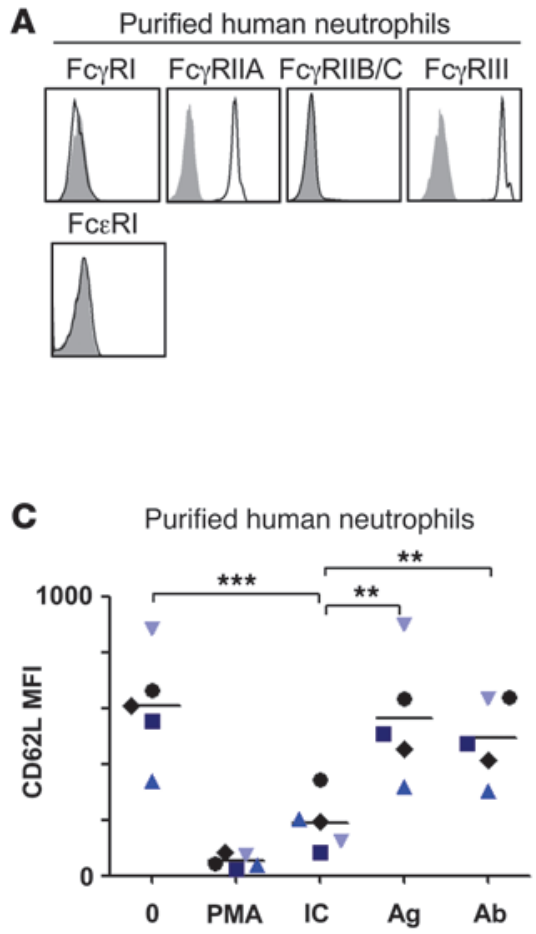

E

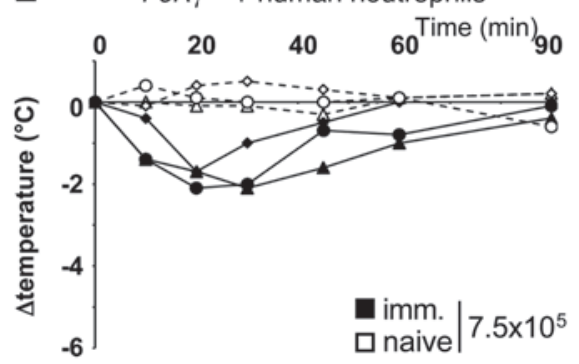

B

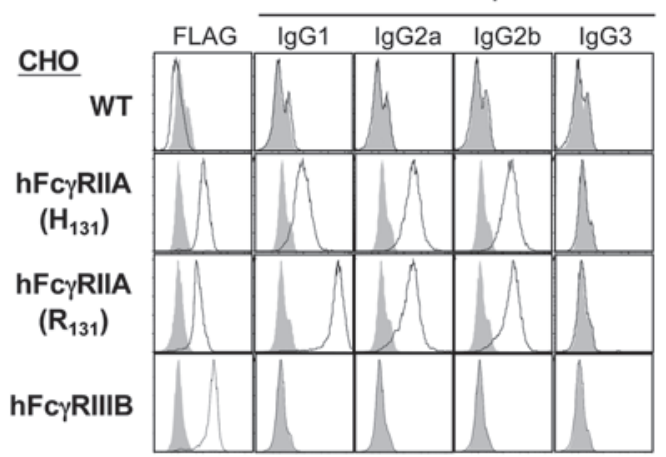

D

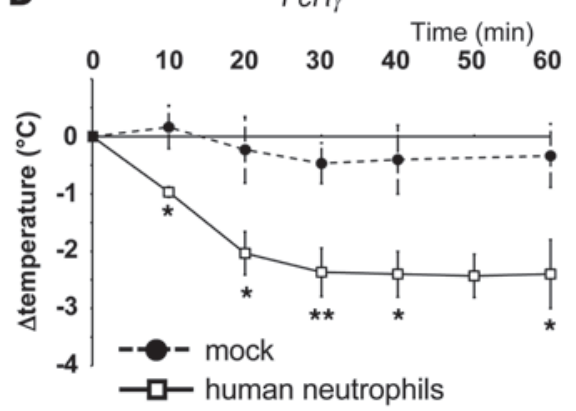

$\mathbf{F}$

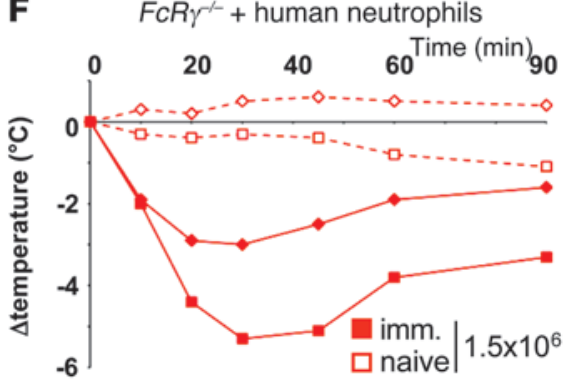

\section{Figure 8}

Human neutrophils restore anaphylaxis in resistant mice. (A) Representative histogram plots of human FcR expression on purified human neutrophils. (B) Histograms show the binding of indicated IgG IC or anti-FLAG mAbs (FLAG) to indicated FLAG-tagged $\mathrm{Fc} \gamma \mathrm{R}^{+} \mathrm{CHO}$ transfectants. Both polymorphic variants of human FcyRIIA at position 131 are used and represented. All human Fc $\gamma$ RIIIB variants (NA1, NA2, and $\mathrm{SH}$ ) gave identical results; only variant NA1 is represented. (C) Expression of CD62L on purified human neutrophils from healthy donors incubated with GPI/anti-GPI IC $(n=5)$ and controls. Data represent individual results and means. (D) $F c R \gamma^{-1-}$ mice were immunized with BSA, injected or not with $2 \times 10^{6}$ human neutrophils, challenged with BSA, and central temperatures monitored $(n=3)$. Data are represented as mean \pm SEM. Statistical differences are indicated. (E and $\mathbf{F})$ Purified human neutrophils originating from 1 healthy donor were divided equally in 2 fractions. One fraction was injected into a naive (open symbols) and 1 fraction into a BSA-immunized $\mathrm{FCR}_{\mathrm{C}} \mathrm{\gamma}^{-1-}$ mice (closed symbols) at (E) $7.5 \times 10^{5}$ neutrophils per mouse $(n=3)$ or $(\mathbf{F}) 1.5 \times 10^{6}$ neutrophils per mouse $(n=2)$. Mice were subsequently challenged with BSA and central temperatures were monitored. Each symbol corresponds to the pair of mice that received neutrophils from 1 specific donor. ${ }^{*} P<0.05$; ${ }^{\star \star} P<0.01 ;{ }^{* *} P<0.001$.
ASA was virtually abrogated in CPLA2-deficient mice (our results and ref. 29), which cannot generate several lipid-derived mediators, including PAF. Activated neutrophils $(20,22)$, monocytes/macrophages (35), and eosinophils (36) all produce PAF, but neutrophils were reported to be major producers (21). We found, indeed, that neutrophils secrete PAF when stimulated by IgG2b-IC, but we also found elevated PAF levels in plasma of mice undergoing neutrophil-dependent PSA. Together our results suggest that PAF released upon neutrophil activation during ASA and PSA is responsible for anaphylactic shock.

ASA depends on activating receptors (5) that associate with and whose expression and signaling depend on FcR $\gamma$. These are Fc $\gamma \mathrm{RI}$, Fc $\gamma$ RIIIA, Fc $\gamma$ RIV, and FceRI (37). ASA was reported in IgE-deficient mice (12), and we observed that it was comparable in WT and FceRI-deficient mice. Similarly, the deletion of FceRI did not affect ASA in mice immunized with antigen in alum $(5,38)$. While

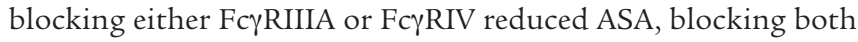
receptors abrogated ASA in WT mice. IgG antibodies seem therefore more important than IgE antibodies in ASA following immunization in CFA/IFA. Fc $\gamma$ RIV contributed to ASA in WT mice, and it was necessary and sufficient to induce ASA in $5 \mathrm{KO}$ mice. Although Fc $\gamma$ RIV are expressed by neutrophils and by monocytes/ macrophages (18), only neutrophil Fc $\gamma$ RIV accounts for ASA in
5KO mice. A single activating Fc $\gamma \mathrm{R}$ on a single cell population is therefore sufficient to induce ASA. Our results demonstrate that FcyRIIIA or Fc $\gamma$ RIV is responsible for ASA following CFA/IFA immunizations, and that each could substitute for the other to induce ASA, provided that IgG2 antibodies are produced.

That IgG1 can induce anaphylaxis was demonstrated by PSA. The only activating FcR having an affinity for IgG1 is FcyRIIIA $(17,18)$. Depletion of basophils using specific mAbs abrogated IgG1-induced PSA (10), although mast cells and neutrophils also express Fc $\gamma$ RIIIA. A model of basophil-deficient mice, however, challenges this result (14). Mast cells are necessary for IgE-induced PSA, although basophils also express FceRI. Noticeably, IgEinduced PSA was abolished in $5 \mathrm{KO}$ mice (data not shown). Fc $\gamma \mathrm{RIV}$ that can bind $\operatorname{IgE}$ with a low affinity (17) is therefore insufficient to trigger this reaction. IgG1 is the predominant antibody subclass following immunization in alum, but also in CFA/IFA. IgG1 antibodies are likely to act as the main players in ASA by engaging Fc $\gamma$ RIIIA. BSA immunizations in alum induced specific IgG1, but not specific IgG2 (Supplemental Figure 4D), indicating that Fc $\gamma$ RIIIA, but not Fc $\gamma$ RIV, were engaged during ASA following this immunization protocol. Supporting this conclusion, Fc $\gamma$ RIV was not sufficient to induce ASA in $5 \mathrm{KO}$ mice following immunization in alum (Supplemental Figure 4E). 
We found, however, that not only IgG1, but also IgG2, antibodies could induce PSA. IgG2-induced PSA could develop in $5 \mathrm{KO}$ mice, and neutrophils contributed to the shock. IgG2 can therefore contribute to anaphylaxis. IgG2-IC that may form in vivo upon antigen challenge following immunization in CFA/IFA may be responsible for the predominant role of neutrophils as IgG2

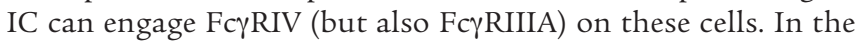
absence of IgG2 antibodies, as in ASA following immunization with antigen in alum, IgG1-IC may trigger Fc $\gamma$ RIIIA-expressing basophils and neutrophils. It follows that basophils contribute to ASA and to PSA when IgG1-IC are present (this report and ref. 10 ), but also other cells (14), among which are neutrophils. Our results indicating that neutrophils are mandatory for polyclonal IgG-induced PSA differ from previous reports implicating mast cells (5) and basophils (10) in IgG1-induced PSA. They are, however, not contradictory. Indeed, monoclonal IgG1-IC can selectively engage Fc $\gamma$ RIIIA, while IgG-IC made of IgG1 and IgG2 isotypes will engage both Fc $\gamma$ RIIIA and Fc $\gamma$ RIV, to induce PSA. FcR-expressing cells involved in each type of PSA may therefore be different. Taken together, these data suggest that IgE, IgG1, and IgG2 can all induce anaphylaxis when engaging FceRI, Fc $\gamma$ RIIIA, and Fc $\gamma$ RIV on mast cells, basophils, and neutrophils, respectively. Although likely, it was not formally demonstrated that FceRI or Fc $\gamma$ RIIIA alone could induce ASA. Using the $5 \mathrm{KO}$ model, we provide evidence that Fc $\gamma$ RIV alone can. Because Fc $\gamma$ RIV is a receptor for IgG2, but not for IgG1, and is expressed by neutrophils, but not by basophils or mast cells, we are able to demonstrate here a role for the most unexpected antibody, receptor, and cell type in ASA in mice.

Human anaphylaxis is essentially active. IgG1 is the most abundant IgG subclass in human plasma, and the majority of antibodies raised by vaccinations (generally in alum) belong to this subclass. Human IgG1 binds to all activating human FcyRs (39). Both specific IgE and IgG antibodies are found in the serum of allergic patients, but the relative concentration of the various classes is poorly known and rarely investigated. FcrRIV has no human ortholog, and FcyRIIIA are not expressed by human neutrophils, basophils, and mast cells (40). These 3 cell types, nevertheless, express activating $\mathrm{Fc}$ receptors. All of them express another activating IgG receptor, Fc $\gamma$ RIIA. Mast cells and basophils also express the high-affinity IgE receptor FceRI in normal individuals as well as neutrophils in atopic patients (41). These 3 cell types can produce PAF upon activation, especially neutrophils (21). PAF could play an important role in human anaphylaxis. Indeed, plasma PAF concentration has been correlated with the severity of shocks in patients (42). Although the cellular source of PAF in human anaphylaxis was not identified, the above-mentioned results endow neutrophils with a critical role. Supporting this assumption, IgG-IC could activate human neutrophils in vitro, and a transfer of human neutrophils restored ASA in FcR $\gamma$-deficient mice.

In conclusion, we demonstrate here a previously unexpected role of neutrophils in anaphylaxis. An IgG2-induced, Fc $\gamma$ RIV-dependent, PAF-mediated active anaphylaxis, contingent on neutrophils, could be unraveled using immunized multiple FcR-deficient mice. IgG-induced, Fc $\gamma$ R-dependent, PAF-mediated ASA was also observed in WT mice, to which neutrophils contributed. Anaphylaxis induction is therefore a property of neutrophils, which is not trivial considering that neutrophils are the most numerous cells among blood leukocytes in humans. This may have important therapeutic consequences if indeed neutrophils can induce IgGdependent anaphylactic reactions in humans.

\section{Methods}

Mice. 5KO (N6 B6) mice have been described (17). cPla2 $2^{-/-}$mice (129/B6) were provided by J. Bonventre (Brigham and Women's Hospital, Harvard Institutes of Medicine, Boston, Massachusetts, USA); KRN transgenic mice were provided by D. Mathis and C. Benoist (Harvard Medical School, Boston, Massachusetts, USA) and the Institut de Génétique et de Biologie Moleculaire et Cellulaire (Illkrich, France). WT C57BL/6J and NOD mice were purchased from Charles River, and W/sh/W/sh, FcyRIIIA ${ }^{-/-}$ and $F c R \gamma^{-/-}$C57BL/6J mice from Jackson Laboratories. Rag2 $2^{-/}$mice were used to generate $\mathrm{Rag}^{-{ }^{--}} 5 \mathrm{KO}$ and $\mathrm{Rag} 2^{-/-} \mathrm{FcR} \gamma^{-/-}$mice by intercrosses. All mouse protocols were approved by the Animal Care and Use Committees of Paris, Île de France, France.

Antibodies, reagents, and cells. PBS- and clodronate-liposomes were prepared as previously described (19). Alum hydroxide gel, pertussis toxin, BSA, DNP-HSA, rabbit GPI, gadolinium(III) chloride, CFA and IFA, CV-3988, ABT-491, cyproheptadine, and luminol were obtained from Sigma-Aldrich; anti-mouse CD11b, CD4, CD19, Gr1, SiglecF, CD117, IgE, and antihuman Fc $\gamma$ RI, Fc $\gamma$ RIII, CD62L were from BD Biosciences; anti-mouse DX5, mFceRI, and anti-hFceRI were from eBioscience; anti-mFcyRI (290322) and mFc $\gamma$ RIIIA (275003) were from R\&D Systems; anti-hFc $\gamma$ RIIA mAbs (IV.3) were from StemCell Technologies; mouse IgG3 anti-DNP were from Serotec; and the MPO ELISA kit was from HyCult Biotech. The hybridomas producing mAbs anti-mFcrRIV (9E9) were provided by J.V. Ravetch (Rockefeller University, New York, New York, USA); anti-Gr1 (RB6-8C5) was provided by R. Coffman (DNAX Research Institute, Palo Alto, California, USA); mIgG2a anti-platelet (6A6) was provided by R. Good (University of South Florida College of Medicine, Tampa, Florida, USA); and mIgG1 and mIgG2b anti-DNP was provided by B. Heyman (Uppsala Universitet, Uppsala, Sweden). Purified mAbs anti-hFcyRIIB/C (GB3) were provided by U. Jacob (SuppreMol GmbH); anti-CCR3 was provided by J.J. Lee (Mayo Clinic, Scottsdale, Arizona, USA). Anti-CD200R3 (Ba103) was produced as described (10). CHO K1 cells stably transfected with FLAG-tagged mouse FcyRs (17) or human FLAG-tagged Fc $\gamma$ Rs (39) were cultured as described.

Flow cytometry analysis. Cells were stained with indicated fluorescently labeled $\mathrm{mAbs}$ for 30 minutes at $0^{\circ} \mathrm{C}$.

IC binding. Mouse IC were preformed by incubating $10 \mu \mathrm{g} / \mathrm{ml} \mathrm{DNP}_{16^{-}}$ BSA-biotin with $15 \mu \mathrm{g} / \mathrm{ml}$ anti-DNP mAbs for 1 hour at $37^{\circ} \mathrm{C} .2 \times 10^{5}$ cells, preincubated or not with indicated blocking $\mathrm{mAbs}$, were incubated with IC for 2 hours at $4^{\circ} \mathrm{C}$, which were detected using neutravidin-PE at $2 \mu \mathrm{g} / \mathrm{ml}$ for 30 minutes at $4^{\circ} \mathrm{C}$.

ASA. 6- to 9-week-old male mice were used for ASA. They were injected i.p. at days 0,14, and 28 with $200 \mu \mathrm{g}$ BSA, either once in CFA and twice in IFA, or 3 times in alum, or 3 times in alum plus Pertussis toxin. BSA-specific $\operatorname{IgG} 1$ and $\operatorname{IgG} 2 \mathrm{a} / \mathrm{b} / \mathrm{c}$ antibodies in serum were titered by ELISA at day 30 . Briefly, BSA-coated plates were sequentially incubated with dilutions of serum, HRP-labeled anti-Ig isotype antibodies, and SIGMAFAST OPD solution. Internal negative (serum from naive $\mathrm{C} 57 \mathrm{BL} / 6 \mathrm{~J} \mathrm{mice}$ ) and positive (pool of serum of BSA-immunized C57BL/6J mice) controls were added to all test plates to define a background value and a "value 1 " in arbitrary units, respectively. High titers of IgG1 antibodies were found in mice immunized using either CFA/IFA or alum immunization protocol. IgG2 antibodies were detected in mice immunized using CFA and IFA only. Absolute counts and proportions of granulocytes in peripheral mouse blood were determined using an $\mathrm{ABC}$ Vet automatic blood analyzer (Horiba ABX).

Mice with comparable antibody titers were challenged i.v. with $500 \mu \mathrm{g}$ BSA (unless otherwise specified) 10 days after the last immunization. Note that the amount of antigen that induced ASA (Supplemental Figure 5A) was similar to that reported to be required for IgG-induced PSA (43). Central temperature was monitored using a digital thermometer (YSI), and time of death was recorded. Except in Figure 1, E and F, and in Figure 2A, data presented in 
each figure correspond to 1 representative experiment. Supplemental Table 1 lists the total number of mice that were used for indicated experimental conditions, their grades of anaphylactic shock, and the mortality rate.

PSA. Mice were injected i.v. with preformed IC made of $20 \mu \mathrm{K} / \mathrm{BxN}$ serum and $50 \mu \mathrm{g}$ GPI (Figure 4B); $500 \mu \mathrm{g}$ IgG2b mAb anti-DNP and $200 \mu \mathrm{g}$ DNP-HSA (Figure 3, A, B, and D); and IC made of $100 \mu \mathrm{l} \mathrm{K/BxN}$ serum and $40 \mu \mathrm{g}$ GPI (Figure 3, E-I). Alternatively (Supplemental Figure 1B), $500 \mu \mathrm{l}$ of serum from BSA-immunized mice collected on day 30 was injected i.v. into naive mice and mice were challenged 3 hours later with an i.v. injection of $500 \mu \mathrm{g}$ BSA. Central body temperature was recorded using a digital thermometer (YSI).

Experimental immune thrombocytopenia. Blood samples were taken retroorbitally before and at indicated time points after the i.v. injection of $5 \mu \mathrm{g}$ of anti-platelet mAb 6A6. Platelet counts were determined using an ABC Vet automatic blood analyzer (Horiba ABX).

In vivo blocking and depletion. $200 \mu \mathrm{g} / \mathrm{mouse}$ of anti-Fc $\mathrm{RIV} \mathrm{mAbs}$ were injected i.v. 30 minutes before challenge. $50 \mu \mathrm{g} /$ mouse of anti-Fc $\gamma$ RIIIA mAbs, $2.1 \mathrm{mg} / \mathrm{mouse}$ of PBS- or clodronate-liposomes, $300 \mu \mathrm{g} / \mathrm{mouse}$ of anti-Gr1 or anti-CCR $3 \mathrm{mAbs}$, and $30 \mu \mathrm{g} /$ mouse of anti-CD200R $3 \mathrm{mAbs}$ or $1 \mathrm{mg} / \mathrm{mouse}$ of gadolinium were injected 24 hours before challenge. $66 \mu \mathrm{g} / \mathrm{mouse}$ CV-3988, $25 \mu \mathrm{g} /$ mouse ABT-49, or $50 \mu \mathrm{g} /$ mouse cyproheptadine was injected i.v. 10, 20, or i.p. 30 minutes before challenge, respectively.

Depletion of cell populations was ascertained for specificity of the depletion using flow cytometry on blood samples taken during or after the experiment (as represented in the figures, or in examples shown in Supplemental Figure 1D, Supplemental Figure 2, A and B, and Supplemental Figure 3, D and E). Depletion of specific cell populations or efficiency of blocking antibodies was also controlled using the macrophage-dependent experimental immune thrombocytopenia (ITP) model: ITP in 5KO mice was inhibited by Fc $\gamma$ RIV blockade (Supplemental Figure 5B), as expected (18), was inhibited by monocyte/macrophage depletion using toxic liposomes (Supplemental Figure 5C), as expected (44), and was unaltered by neutrophil depletion (Supplemental Figure 5D).

Bioluminescence imaging. Bioluminescence from depilated and anesthetized mice injected i.p. with $15 \mathrm{mg} / \mathrm{mouse}$ luminol was acquired on an IVIS 100 (Caliper Life Sciences) using 2-5 minute exposure times with medium binning. Average radiance (photons $/$ seconds $/ \mathrm{cm}^{2} /$ surface radiance) and total photon flux of indicated regions of interest (Figure 2C) were calculated using Living Image software.

Purification, in vitro stimulation, and transfer of mouse neutrophils. For in vitro analysis, murine neutrophils were purified (>95\% purity) from bone marrow suspensions using anti-Ly6G microbead kits (Miltenyi Biotec). $1.4 \times 10^{5}$ neutrophils were challenged with plate-bound stimulants or PMA plus thapsigargin for 1 hour. CD62L expression was assessed by flow cytometry and MPO by ELISA on cell supernatants.

For in vivo transfer, neutrophils were recovered from bone marrow suspensions following double-gradient centrifugation (Histopaque-1119, Ficoll-Paque PLUS: 50/50 v/v). $3 \times 10^{6}$ neutrophils were injected i.v. into BSA-immunized mice 20 minutes before challenge.

Measurement of PAF in vitro. Purified neutrophils $\left(1 \times 10^{6}\right.$ cells in $\left.0.1 \mathrm{ml}\right)$ were incubated on plate-bound DNP-HSA alone (Ag; at $10 \mu \mathrm{g} / \mathrm{ml}$ ) or plate-bound DNP-HSA (at $10 \mu \mathrm{g} / \mathrm{ml}$ ) plus anti-DNP IgG2b GORK (IC; at $100 \mu \mathrm{g} / \mathrm{ml}$ ) in HBSS buffer supplemented with $1.26 \mathrm{mM} \mathrm{CaCl}_{2}$ and $0.9 \mathrm{mM} \mathrm{MgCl}_{2}$. When indicated, neutrophils were preincubated with $20 \mu \mathrm{g} / \mathrm{ml}$ of anti-FcyRIV mAbs. Culture supernatants were collected after 20 minutes at $37^{\circ} \mathrm{C}$.

Measurement of PAF in vivo. $100 \mu \mathrm{l}$ of plasma was collected from mice undergoing monoclonal IgG2b PSA (IC made of $1 \mathrm{mg}$ IgG2b mAb antiDNP and $300 \mu \mathrm{g}$ DNP-HSA) at $t=20$ minutes following challenge. When indicated, mice were preinjected with $200 \mu \mathrm{g} / \mathrm{ml}$ of anti-Fc $\gamma \mathrm{RIV}$ Ab $30 \mathrm{~min}$ utes before challenge.
Culture supernatants or plasma were mixed $1: 10 \mathrm{v} / \mathrm{v}$ in methanol, centrifuged at $16,100 \mathrm{~g}$ for 10 minutes; supernatants were frozen at $-20^{\circ} \mathrm{C}$. After adding deuterized PAF (PAF-d4; Cayman Chemical) as an internal standard to supernatants, PAF-containing lipids were extracted with Oasis HLB solid phase extraction cartridge (10 mg/ml; Waters) as described (45). PAF was quantified using liquid chromatography-tandem mass spectrometry on a TSQ Quantum Ultra mass spectrometer (Thermo Fisher Scientific) that was operated in negative electrospray ionization. HPLC conditions and mass spectrometry parameters were described previously (45). The selected reaction monitoring (SRM) modes was used to monitor 568.5 to $59 \mathrm{~m} / \mathrm{z}$ transitions for PAF and 572.5 to $59 \mathrm{~m} / \mathrm{z}$ transitions for PAF-d4. Commercial PAF (Cayman Chemical) mixed with PAF-d4 was used to draw calibration curves, and data were processed using the Xcalibur 2.0 software (Thermo Fisher Scientific). PAF values of less than 5 pg should be considered under the lower detection limit (Figure 2B and Figure 3C).

Purification and transfer of human neutrophils. Human granulocytes were purified (>95\% purity) from normal heparinized blood by double-gradient centrifugation (Histopaque-1119, Ficoll-Paque Plus: 50/50 v/v) and using antiCD15 microbeads (Miltenyi Biotec). For transfer experiments, neutrophils were injected i.v. 15 minutes prior to BSA challenge. For in vitro analysis, $2 \times 10^{5}$ neutrophils were stimulated for 1 hour at $37^{\circ} \mathrm{C}$ with $100 \mathrm{nM}$ PMA or IC (30 $\mu \mathrm{g} / \mathrm{ml} \mathrm{GPI}$ and $1 / 100$ dilution of $\mathrm{KxB} / \mathrm{N}$ serum) or neutrophils with plate-bound IC (DNP-HSA and indicated mouse anti-DNP antibodies).

Statistics. Data were analyzed using 1-way ANOVA with Bonferroni's post-test (Figure 6A, Figure 8C, and Supplemental Figure 4B) or 2-tailed Student's $t$ test (all other data). $P<0.05$ was considered significant.

\section{Acknowledgments}

We are thankful to F. Hamano (The University of Tokyo, Tokyo, Japan) for help with PAF measurements, to A.-M. Nicola and the Plate-Forme d'Imagerie Dynamique (Institut Pasteur, Paris) for help with the bioluminescence experiments, to C. Detchepare for administrative help, and to G. Eberl and P. Bousso (Institut Pasteur, Paris) for critical reading of the manuscript. We are thankful to our colleagues for their generous gifts: S. Verbeek (Leiden University Medical Center, Leiden, The Netherlands), J.-P. Kinet (Harvard Institutes of Medicine, Boston, Massachusetts, USA), M. Lamers (Max-Planck-Institut für Immunbiologie, Freiburg, Germany), D. Mathis and C. Benoist (Harvard Medical School, Boston, Massachusetts, USA) and the Institut de Génétique et de Biologie Moléculaire et Cellulaire (Illkirch, France) for mice; R. Coffman, R. Good, B. Heyman, J.J. Lee, and J.V. Ravetch for antibodies. We thank J. Bonventre and E. O'Leary (Brigham and Women's Hospital, Harvard Institutes of Medicine, Boston, Massachusetts, USA) for $c P L A 2^{-/-}$mice, and F. Bourgade and K. Sebastien (Centre des Opérations Sanitaires de l'Animalerie Centrale, Institut Pasteur, Paris, France) for their breeding and housing. We thank M. Aubier (Service de Pneumologie, Hôpital Bichat, Paris, France) for advice on human neutrophil transfer, A. Herbelin (INSERM U935, Hôpital Paul Brousse, Villejuif, France) for advice on alum immunization protocols, and X. Zhang (Institut Pasteur, Paris) for advice on neutrophil purification. $\mathrm{Cl}_{2} \mathrm{MDP}$ was a gift of Roche Diagnostics $\mathrm{GmbH}$. This work was supported by the Institut Pasteur, the Institut National de la Santé et de la Recherche Médicale (INSERM), the Agence Nationale de la Recherche (ANR) (grants 05-JCJC0236-01 and GENOPAT-09-GENO-014-01), the Fondation pour la Recherche Médicale (FRM) (Programme Allergie 2007), by funding under the Sixth Research Framework Programme of the European Union, Project MUGEN (MUGEN LSHG-CT-2005-005203), by the Société Française d'Allergologie (SFA) (Soutien de la recher- 
che en allergologie 2010) and the Balsan company. F. Jönsson was financially supported by ANR, MUGEN, and is currently a recipient of a fellowship from the FRM. D.A. Mancardi was financially supported by FRM and is currently a recipient of a fellowship from the Institut Pasteur (Bourse Roux). T. Shimizu and Y. Kita are supported in part by Grants-in-Aid from the Ministry of Education, Science, Culture, Sports and Technology of Japan.
Received for publication September 27, 2010, and accepted in revised form January 19, 2011.

Address correspondence to: Pierre Bruhns, Unité d'Allergologie Moléculaire et Cellulaire, Département d'Immunologie, Institut Pasteur, 25 rue du Docteur Roux, 75015 Paris, France. Phone: 33.1.4568.8629; Fax: 33.1.4061.3160; E-mail: bruhns@pasteur.fr.
1. Galli SJ. Pathogenesis and management of anaphylaxis: current status and future challenges. J Allergy Clin Immunol. 2005;115(3):571-574.

2. Neugut AI, Ghatak AT, Miller RL. Anaphylaxis in the United States: an investigation into its epidemiology. Arch Intern Med. 2001;161(1):15-21.

3. Portier P, Richet C. De l'action anaphylactique de certain venins. CR Soc Biol (Paris). 1902;54:170.

4. Dombrowicz D, Flamand V, Brigman KK, Koller BH, Kinet JP. Abolition of anaphylaxis by targeted disruption of the high affinity immunoglobulin $\mathrm{E}$ receptor alpha chain gene. Cell. 1993;75(5):969-976.

5. Miyajima I, Dombrowicz D, Martin TR, Ravetch JV, Kinet JP, Galli SJ. Systemic anaphylaxis in the mouse can be mediated largely through $\operatorname{IgG} 1$ and Fc gammaRIII. Assessment of the cardiopulmonary changes, mast cell degranulation, and death associated with active or IgE- or IgG1-dependent passive anaphylaxis. J Clin Invest. 1997;99(5):901-914.

6. Makabe-Kobayashi Y, et al. The control effect of histamine on body temperature and respiratory function in IgE-dependent systemic anaphylaxis. J Allergy Clin Immunol. 2002;110(2):298-303.

7. Kimura S, Watanabe A, Takeuchi M, Nagata M, Harada M. Suppressive effects of antihistaminic and/or anti-PAF agents on passive anaphylactic shock in mice sensitized with allogeneic monoclonal IgE and IgG1 antibodies and hyperimmune serum. Immunol Invest. 1998;27(6):379-393.

8. Daëron M, Bonnerot C, Latour S, Fridman WH. Murine recombinant Fc gamma RIII, but not Fc gamma RII, trigger serotonin release in rat basophilic leukemia cells. J Immunol. 1992;149(4):1365-1373.

9. Hazenbos WL, et al. Impaired IgG-dependent anaphylaxis and Arthus reaction in Fc gamma RIII (CD16) deficient mice. Immunity. 1996;5(2):181-188.

10. Tsujimura $Y$, et al. Basophils play a pivotal role in immunoglobulin-G-mediated but not immunoglobulin-E-mediated systemic anaphylaxis. Immunity. 2008;28(4):581-589.

11. Million M, Fioramonti J, Zajac JM, Bueno L. Effects of neuropeptide FF on intestinal motility and temperature changes induced by endotoxin and platelet-activating factor. Eur J Pharmacol. 1997; 334(1):67-73.

12. Oettgen HC, Martin TR, Wynshaw-Boris A, Deng C, Drazen JM, Leder P. Active anaphylaxis in IgEdeficient mice. Nature. 1994;370(6488):367-370.

13. Choi IH, et al. Immunoglobulin E-dependent active fatal anaphylaxis in mast cell-deficient mice. J Exp Med. 1998;188(9):1587-1592.

14. Ohnmacht C, Schwartz C, Panzer M, Schiedewitz I, Naumann R, Voehringer D. Basophils orchestrate chronic allergic dermatitis and protective immunity against helminths. Immunity. 2010;33(3):364-374.

15. Ishii $\mathrm{S}$, et al. Impaired anaphylactic responses with intact sensitivity to endotoxin in mice lacking a platelet-activating factor receptor. J Exp Med. 1998;187(11):1779-1788.

16. Arias K, et al. Concurrent blockade of platelet-acti- vating factor and histamine prevents life-threatening peanut-induced anaphylactic reactions. J Allergy Clin Immunol. 2009;124(2):307-314.

17. Mancardi DA, Iannascoli B, Hoos S, England P, Daeron M, Bruhns P. FcgammaRIV is a mouse IgE receptor that resembles macrophage FcepsilonRI in humans and promotes IgE-induced lung inflammation. J Clin Invest. 2008;118(11):3738-3750.

18. Nimmerjahn F, Bruhns P, Horiuchi K, Ravetch JV. Fc gamma RIV: a novel FcR with distinct IgG subclass specificity. Immunity. 2005;23(1):41-51.

19. Van Rooijen N, Sanders A. Liposome mediated depletion of macrophages: mechanism of action, preparation of liposomes and applications. J Immunol Methods. 1994;174(1-2):83-93.

20. Lotner GZ, Lynch JM, Betz SJ, Henson PM. Human neutrophil-derived platelet activating factor. J Immunol. 1980;124(2):676-684.

21. Jouvin-Marche E, Ninio E, Beaurain G, Tence M, Niaudet P, Benveniste J. Biosynthesis of Paf-acether (platelet-activating factor). VII. Precursors of Pafacether and acetyl-transferase activity in human leukocytes. J Immunol. 1984;133(2):892-898.

22. Virella G, et al. Release of PAF by human polymorphonuclear leucocytes stimulated by immune complexes bound to Sepharose particles and human erythrocytes. Immunology. 1983;50(1):43-51.

23. Klebanoff SJ. Myeloperoxidase: friend and foe. J Lenkoc Biol. 2005;77(5):598-625.

24. Gross $S$, et al. Bioluminescence imaging of myeloperoxidase activity in vivo. Nat Med. 2009;15(4):455-461.

25. Maccioni M, et al. Arthritogenic monoclonal antibodies from K/BxN mice. J Exp Med. 2002; 195(8):1071-1077.

26. Mancardi DA, et al. The murine high-affinity IgG receptor $\mathrm{Fc}$ (gamma)RIV is sufficient for autoantibody-induced arthritis. I Immunol. 2011;186(4):1899-1903.

27. Braun A, et al. STIM1 is essential for Fcgamma receptor activation and autoimmune inflammation. Blood. 2009;113(5):1097-1104.

28. Bonventre JV, et al. Reduced fertility and postischaemic brain injury in mice deficient in cytosolic phospholipase A2. Nature. 1997;390(6660):622-625.

29. Uozumi N, et al. Role of cytosolic phospholipase A2 in allergic response and parturition. Nature. 1997; 390(6660):618-622.

30 . Kennedy BP, et al. A natural disruption of the secretory group II phospholipase A2 gene in inbred mouse strains. J Biol Chem. 1995;270(38):22378-22385.

31. Kimberly RP, Ahlstrom JW, Click ME, Edberg JC. The glycosyl phosphatidylinositol-linked Fc gamma RIIIPMN mediates transmembrane signaling events distinct from Fc gamma RII. J Exp Med. 1990;171(4):1239-1255

32. Meknache N, Jönsson F, Laurent J, Guinnepain MT, Daëron M. Human Basophils Express the Glycosylphosphatidylinositol-Anchored Low-Affinity IgG Receptor Fc\{gamma\}RIIIB (CD16B).J Immunol. 2009;182(4):2542-2550.
33. Strait RT, Morris SC, Yang M, Qu XW, Finkelman FD. Pathways of anaphylaxis in the mouse. J Allergy Clin Immunol. 2002;109(4):658-668.

34. Xu X, et al. Neutrophil histamine contributes to inflammation in mycoplasma pneumonia. J Exp Med. 2006;203(13):2907-2917.

35. Camussi G, Aglietta M, Coda R, Bussolino F, Piacibello W, Tetta C. Release of platelet-activating factor (PAF) and histamine. II. The cellular origin of human PAF: monocytes, polymorphonuclear neutrophils and basophils. Immunology. 1981; 42(2):191-199.

36. Lee TC, Malone B, Wasserman SI, Fitzgerald V, Snyder F. Activities of enzymes that metabolize platelet-activating factor (1-Alkyl-2-acetyl-snglycero-3-phosphocholine) in neutrophils and eosinophils from humans and the effect of a calcium ionophore. Biochem Biophys Res Commun. 1982; 105(4):1303-1308.

37. Ra C, Jouvin MH, Blank U, Kinet JP. A macrophage Fc gamma receptor and the mast cell receptor for IgE share an identical subunit. Nature. 1989; 341(6244):752-754.

38. Dombrowicz D, Flamand V, Miyajima I, Ravetch JV, Galli SJ, Kinet JP. Absence of Fc epsilonRI alpha chain results in upregulation of Fc gammaRIIIdependent mast cell degranulation and anaphylaxis. Evidence of competition between Fc epsilonRI and Fc gammaRIII for limiting amounts of FcR beta and gamma chains. J Clin Invest. 1997;99(5):915-925.

39. Bruhns $P$, et al. Specificity and affinity of human Fc\{gamma\} receptors and their polymorphic variants for human IgG subclasses. Blood. 2009; 113(16):3716-3725.

40. Daëron M. Fc receptor biology. Annu Rev Immunol. 1997;15:203-234.

41. Gounni AS, Lamkhioued B, Koussih L, Ra C, Renzi PM, Hamid Q. Human neutrophils express the high-affinity receptor for immunoglobulin E (Fc epsilon RI): role in asthma. FASEB J. 2001; 15(6):940-949.

42. Vadas P, et al. Platelet-activating factor, PAF acetylhydrolase, and severe anaphylaxis. $N$ Engl J Med. 2008;358(1):28-35.

43. Strait RT, Morris SC, Finkelman FD. IgG-blocking antibodies inhibit IgE-mediated anaphylaxis in vivo through both antigen interception and Fc gamma RIIb cross-linking. J Clin Invest. 2006; 116(3):833-841.

44. Alves-Rosa F, Stanganelli C, Cabrera J, van Rooijen N, Palermo MS, Isturiz MA. Treatment with liposome-encapsulated clodronate as a new strategic approach in the management of immune thrombocytopenic purpura in a mouse model. Blood. 2000; 96(8):2834-2840.

45. Kita Y, Takahashi T, Uozumi N, Shimizu T. A multiplex quantitation method for eicosanoids and platelet-activating factor using column-switching reversed-phase liquid chromatography-tandem mass spectrometry. Anal Biochem. 2005;342(1):134-143. 